\title{
Recovery of phosphorus from sewage sludge ash: Influence of incineration temperature on ash mineralogy and related phosphorus and heavy metal extraction
}

\author{
Lorien $\underline{\text { Luyckx }}^{1}$, Jo Van Caneghem ${ }^{1}$ \\ ${ }^{1}$ KU Leuven, Department of Materials Engineering, Sustainable Materials Processing and Recycling (SeMPeR), Group T \\ Leuven Campus, Andreas Vesaliusstraat 13 - box 2600, 3000 Leuven, Belgium \\ Corresponding author: Lorien Luyckx, lorien.luyckx@kuleuven.be
}

ORCID: Lorien Luyckx (0000-0002-2700-7726); Jo Van Caneghem (0000-0002-4052-1260)

\begin{abstract}
Phosphorus (P) can be effectively recovered from sewage sludge ash (SSA) by applying wet chemical extraction techniques. However, considerable amounts of heavy metals can be co-extracted depending on the type of extraction liquid used. In this study, the influence of the incineration temperature on the ash mineralogy and related $\mathrm{P}$ and heavy metal extraction using sulfuric acid, hydrochloric acid, oxalic acid and sodium hydroxide was studied. Results showed that the P extraction efficiency with sodium hydroxide decreased with increasing incineration temperature, related to a decrease in $\mathrm{Al} / \mathrm{Fe}$ phosphates in the SSA. Furthermore, $\mathrm{P}$ extraction efficiency for the acidic extraction liquids reached a maximum for SSA obtained around $850{ }^{\circ} \mathrm{C}(>86 \% \mathrm{P}$ extracted). Heavy metal co-extraction generally decreased with increasing incineration temperature, which could be linked to the immobilization of the heavy metals in the SSA matrix. For all extraction liquids considered, the lowest heavy metal co-extraction was found in SSA samples obtained at $1000{ }^{\circ} \mathrm{C}(<21 \%$ total heavy metals extracted). However, the incorporation of $\mathrm{P}$ into silicate melt agglomerates at that incineration temperature reduced the $\mathrm{P}$ extraction. As a result, an incineration temperature in the range $800-850{ }^{\circ} \mathrm{C}$ offered a good trade-off between high $\mathrm{P}$ extraction and low heavy metal co-extraction.
\end{abstract}

Keywords: Ash mineralogy; Heavy metal extraction; Incineration temperature; Phosphorus extraction; Sewage sludge.

\section{Graphical abstract}

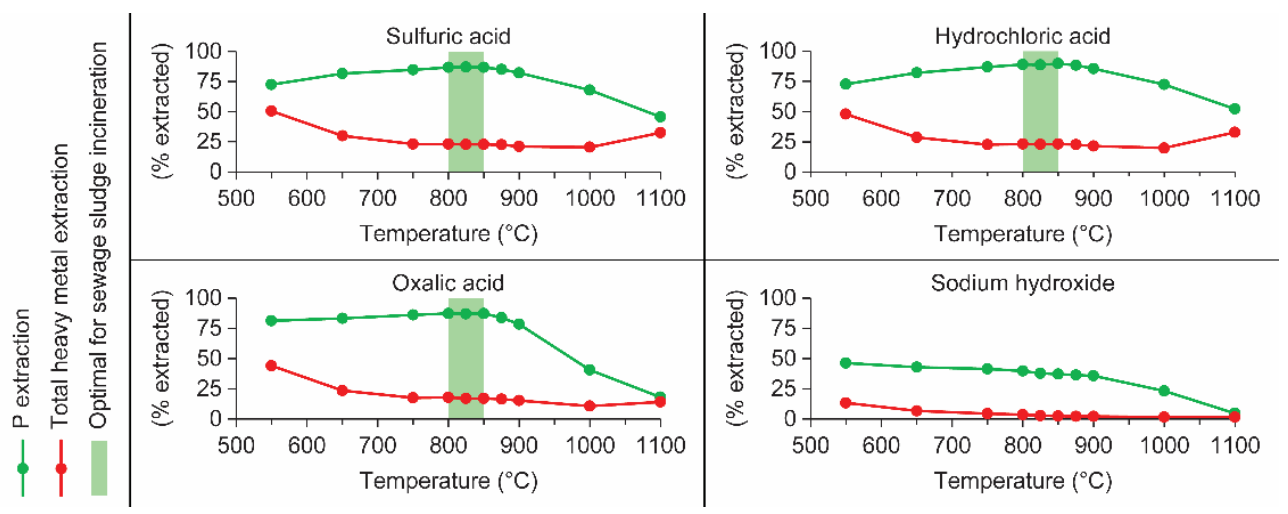

\section{Abbreviations}

See footnote ${ }^{1}$.

\section{Introduction}

Phosphorus (P) is an essential micronutrient for all living organisms. In 2019, the worldwide $\mathrm{P}$ consumption was around 20.5 million tonnes of which most was used for manufacturing fertilizers, animal feed and detergents [1,2]. However, $\mathrm{P}$ reserves, in the form of phosphate rock, are depleting and recycling of $\mathrm{P}$ becomes increasingly important [2].

Wastewater contains high amounts of $\mathrm{P}$ and during wastewater treatment (WWT) more than $90 \%$ of this $\mathrm{P}$ is transferred to the sewage sludge (SS) by applying enhanced biological removal techniques or chemical precipitation with Al- or Fe-salts [3-5]. In 2016, about 11.2 million tonnes (dry matter (DM)) of SS was produced in the EU28, of which about $28 \%$ was incinerated [6]. Incineration not only reduces the mass of the SS by up to $90 \%$, but also destroys pathogens and

\footnotetext{
${ }^{1} \mathrm{DM}=$ dry matter; $\mathrm{EPMA}=$ electron probe microanalysis; ICP-OES = inductively coupled plasma optical emission spectroscopy; $\mathrm{L} / \mathrm{S}=$ liquid/solid; $R_{w p}=$ weighted profile $\mathrm{R}$-factor; $\mathrm{SMT}$ = standards, measurement and testing; $\mathrm{SS}$ = sewage sludge; $\mathrm{SSA}=$ sewage sludge ash; $\mathrm{WWT}=$ wastewater treatment; $\mathrm{XRD}=\mathrm{X}$-ray diffraction .
} 
toxic organic compounds, whilst recovering part of its energy content [3,7,8]. Furthermore, upon incineration, P largely concentrates in the sewage sludge ash (SSA), which generally has a P content of $4-12 \%$. Therefore, SSA is a good alternative for non-renewable phosphate rock, which has a P content of $2-18 \%$ [9-12]. However, both the low $\mathrm{P}$ bioavailability and the high heavy metal concentrations in the SSA exceeding legal limit values for agricultural use, impede the direct application of SSA as a P fertilizer [3,7,13]. In this case, an alternative way to close the $\mathrm{P}$ cycle is to recover the valuable $\mathrm{P}$ from the SSA.

Many experts prefer P recovery from SSA by wet chemical extraction over thermochemical treatment and other recovery methods because of the high efficiency, low costs and because it is similar to the process currently used for extraction of $\mathrm{P}$ from phosphate rock [3,5]. In previous work of the authors, it was found that the type of extraction liquid, extraction liquid concentration, liquid/solid (L/S) ratio, contact time, $\mathrm{pH}$, ash composition and ash mineralogy all affect $\mathrm{P}$ and heavy metal extraction efficiency from SSA [13,14]. Moreover, other literature shows that the temperature at which the SS is incinerated can alter the P mineralogy of the SSA and in this way can also affect the P extractability $[3,8,15,16]$. Higher incineration temperatures stimulate the transformation in the ash of poorly soluble $\mathrm{P}$ minerals, in which $\mathrm{P}$ is bound to $\mathrm{Al}$ or $\mathrm{Fe}(\mathrm{Al} / \mathrm{Fe}$-phosphates), to more soluble $\mathrm{P}$ minerals, in which $\mathrm{P}$ is bound to $\mathrm{Ca}$ or $\mathrm{Mg}(\mathrm{Ca} / \mathrm{Mg}$-phosphates), which improves the $\mathrm{P}$ extraction efficiency and $\mathrm{P}$ bioavailability [3,7,8,16-20]. Gorazda et al. [16] found that the efficiency of $\mathrm{P}$ extraction from SSA with nitric acid increased with increasing SS incineration temperature up to $950{ }^{\circ} \mathrm{C}$. Moreover, the research of Atienza-Martinez et al. [8] showed that higher SS incineration temperatures improved the efficiency of P extraction from SSA with sulfuric acid, whereas this was not the case with oxalic acid, for which the P extraction efficiency was close to $100 \%$ regardless of the SS incineration temperature. The latter was confirmed by the work of Liang et al. [3] (for SS incineration temperatures up to $850^{\circ} \mathrm{C}$ ). Somewhat contradictorily, Liang et al. [3] found that the efficiency of P extraction from SSA with sulfuric acid decreased with increasing SS incineration temperature even though the amount of acid-soluble Ca-phosphates in the ash increased. They related this phenomenon to the denser surface structure of SSA particles formed at higher incineration temperatures, inhibiting acid penetration towards the core of the particles, in this way decreasing the efficiency of $\mathrm{P}$ extraction [3].

The changes in $\mathrm{P}$ mineralogy with increasing SS incineration temperature have been discussed extensively in literature [3,8,16-23]. However, these changes in $\mathrm{P}$ mineralogy have only rarely been linked to the $\mathrm{P}$ extraction efficiency $[3,8,16]$ and, as discussed in the previous paragraph, the results of the little existing studies were not consistent. Moreover, it is important to find out whether the SS incineration temperature also affects the co-extraction of the heavy metals and to which extent [3]. Lower heavy metal co-extraction could reduce the costs of further processing the $\mathrm{P}$ extract to a final product complying with legal limit values for heavy metals in fertilizers.

The primary aim of this study was to assess the influence of the SS incineration temperature on the P mineralogy in the ash and the related wet P extraction efficiency from the SSA in a comprehensive and systematic way. To this extent, the SS incineration temperature was varied between 550 and $1100{ }^{\circ} \mathrm{C}$ and the efficiency of $\mathrm{P}$ extraction from the obtained SSA with sulfuric acid, hydrochloric acid, oxalic acid and sodium hydroxide was investigated. Furthermore, the influence of the SS incineration temperature on the heavy metal co-extraction was investigated.

\section{Materials and methods}

\subsection{SSA samples}

Dewatered SS was sampled from the SS storage bunker at the WWT plant of Aquafin in Leuven (Belgium). One tenth of all SS produced in Flanders (Belgium) is collected in this bunker before it is further treated in a digester. About 1.2 $\mathrm{kg}$ of dewatered SS (25\% DM) was sampled once a day over a ten-day period (February 2020). All SS samples were dried at $105^{\circ} \mathrm{C}$ for $24 \mathrm{~h}$ (VENTI-Line 56 Prime), ground (Retsch RS 200, $30 \mathrm{~s}, 1100 \mathrm{rpm}$ ) and mixed thoroughly with the samples collected on the other days after which the pooled sample was stored in a closed container at room temperature.

Of the pooled SS sample, subsamples of $45 \mathrm{~g}$ each were weighed in a porcelain dish with flat bottom (diameter of 10 $\mathrm{cm}$ ) and incinerated in a muffle furnace (Nabertherm L3/11, heating rate of $15^{\circ} \mathrm{C} / \mathrm{min}$ ) at $550,650,750,800,825,850,875$, 900,1000 and $1100{ }^{\circ} \mathrm{C}$ for $2 \mathrm{~h}$. Next, each SSA sample was left to cool down to room temperature in the ambient air after which it was ground in a mortar and mixed thoroughly. The amount of SS used for the incineration experiments (45 g) was chosen to obtain sufficient amount of SSA for all characterization and extraction experiments, yet assured the SS to be evenly spread in a thin layer over the bottom surface of the porcelain dish. The duration of $2 \mathrm{~h}$ was based on the literature $[3,18,24,25]$ and on preliminary experiments that showed no additional mass loss at longer incineration times.

\subsection{SSA characterization}

The elemental composition of the SSA obtained at the different incineration temperatures was determined by microwave-assisted digestion of $250 \mathrm{mg}$ samples using a combination of aqua regia and hydrofluoric acid, as described in detail in previous work [13]. The digestion solutions were analyzed for $\mathrm{Al}, \mathrm{Ca}, \mathrm{Cd}, \mathrm{Cr}, \mathrm{Cu}, \mathrm{Fe}, \mathrm{K}, \mathrm{Mg}, \mathrm{Na}, \mathrm{Ni}, \mathrm{P}, \mathrm{Pb}, \mathrm{S}, \mathrm{Si}$, $\mathrm{Ti}$ and $\mathrm{Zn}$ by inductively coupled plasma optical emission spectroscopy (ICP-OES) (Varian 720-ES ICP-OES).

The SSA mineralogy in the crystalline phase was determined by quantitative X-ray diffraction (XRD) (D8 Bruker) with a corundum $\left(\mathrm{Al}_{2} \mathrm{O}_{3}\right)$ internal standard and $\mathrm{Cu} \mathrm{K}$ radiation. The data obtained was refined based on the Rietveld method and the weighted profile R-factor $\left(\mathrm{R}_{\mathrm{wp}}\right)$ ranged between 6.50 and 7.59. The obtained XRD spectra can be consulted in Supplementary Material (Figure S1). The 'standards, measurement and testing (SMT)' protocol [26,27] was used to distinguish between inorganic $\mathrm{P}$ and organic $\mathrm{P}$ in the SSA. The same protocol was used to distinguish between $\mathrm{Al} / \mathrm{Fe}$ - 
phosphates (non-apatite inorganic P) and Ca-phosphates (apatite inorganic P) in the SSA. Furthermore, electron probe microanalysis (EPMA) (JXA-8530F) was used to determine the elemental distribution of $\mathrm{Al}, \mathrm{Ca}, \mathrm{Fe}, \mathrm{P}$ and $\mathrm{Si}$ in selected areas of subsamples of the SSA obtained at 550,850 and $1100{ }^{\circ} \mathrm{C}$. The SSA samples obtained at these three temperatures were selected for EPMA as they showed the largest differences in P mineralogy (XRD analysis and SMT protocol) and P extraction efficiency. For EPMA, the powder SSA subsamples were embedded in a resin, grinded, polished and coated with a carbon layer.

\subsection{Extraction experiments}

The extraction liquids selected were sulfuric acid, hydrochloric acid, oxalic acid and sodium hydroxide. Sulfuric acid and oxalic acid were selected since previous work of the authors showed that they were optimal for P extraction from SSA [13]. However, sulfuric acid and oxalic acid have the disadvantage that large amounts of solid extraction residue are formed, i.e., gypsum $\left(\mathrm{CaSO}_{4} .2 \mathrm{H}_{2} \mathrm{O}\right)$ and calcium oxalate $\left(\mathrm{CaC}_{2} \mathrm{O}_{4}\right)$, respectively. These extraction residues require further treatment or a suitable application as secondary resource has to be found [13,28]. Hydrochloric acid was selected because it is available on an industrial scale, and upon extraction, no additional solid residue is formed, only the ash extraction residue remains. Sodium hydroxide was selected because previous work showed that it co-extracts less heavy metals during $\mathrm{P}$ extraction compared to the beforementioned acids [13,14,29,30]. The experiments were carried out at the optimal extraction conditions determined in previous work of the authors [13]: sulfuric acid, hydrochloric acid and oxalic acid were applied at a concentration of $0.5 \mathrm{~N}$, an $\mathrm{L} / \mathrm{S}$ ratio of $10 \mathrm{ml} / \mathrm{g}$ ash and a contact time of $2 \mathrm{~h}$; sodium hydroxide was applied at a concentration of $0.5 \mathrm{~N}$, an $\mathrm{L} / \mathrm{S}$ ratio of $50 \mathrm{ml} / \mathrm{g}$ ash and a contact time of $2 \mathrm{~h}$.

The extraction experiments were carried out at room temperature and all glassware was first rinsed with a $3 \%$ nitric acid solution. A well-sealed $50 \mathrm{ml}$ PP falcon tube (HDPE flat cap) with $2.5 \mathrm{~g}$ of SSA and $25 \mathrm{ml} 0.5 \mathrm{~N}$ sulfuric acid, hydrochloric acid or oxalic acid was placed horizontally on a reciprocating shaker (Heidolph Promax 2020) for $2 \mathrm{~h}$ at maximum speed $(400 \mathrm{rpm})$. The same was done for the experiments with sodium hydroxide but $0.5 \mathrm{~g}$ of SSA was used in combination with $25 \mathrm{ml} 0.5 \mathrm{~N}$ sodium hydroxide. The $\mathrm{pH}$ of the extraction liquid was for each run measured at the start and at the end of the extraction procedure (SenTix 21 electrode). Next, the solutions were filtered $(0.45 \mu \mathrm{m})$ and analyzed for $\mathrm{Al}, \mathrm{Ca}, \mathrm{Cd}, \mathrm{Cr}, \mathrm{Cu}, \mathrm{Fe}, \mathrm{K}, \mathrm{Mg}, \mathrm{Na}, \mathrm{Ni}, \mathrm{P}, \mathrm{Pb}, \mathrm{S}, \mathrm{Si}$, Ti and $\mathrm{Zn}$ by ICP-OES (Varian 720-ES ICP-OES). The extraction efficiency was calculated as the amount of element extracted according to Eq. (1):

Extraction efficiency $(\%)=\frac{\text { Element extracted }(\% \text { of DM) }}{\text { Element in ash }(\% \text { of DM })} \times 100 \%$

\subsection{FactSage thermochemical calculations}

Thermochemical equilibrium calculations were performed with the Equilib module of FactSage (version 8.0), which is based on the Gibbs free energy minimization principle, using FToxid and FactPS databases. These thermochemical calculations were used to predict the heavy metal mineralogy in the SSA. The elemental composition of the SSA samples obtained in the lab experiments (Table 1) was used as input for the thermochemical calculations, in combination with an excess of oxygen.

\subsection{Quality assurance/quality control procedures of analytical techniques}

The microwave assisted digestion was based on the European standard EN 13656:2002 [31]. For the digestion, extraction and SMT protocol, a method/reagent blank was analyzed after going through all steps of the procedure parallel to the SSA samples. The balance, pipettes, $\mathrm{pH}$ meter, and other instruments and measuring devices used were calibrated, standardized and serviced frequently according to internal good laboratory practice standards. A corundum internal standard was used for the quantitative XRD analysis. The calibration curve for the ICP-OES measurements was prepared with 1000 ppm standards and the calibration standards were rerun once each ten or twenty samples measured. All glassware was stored in closed containers and rinsed with at $3 \%$ nitric acid solution before use. Ultrapure water was used for all experiments (18.2

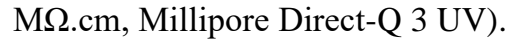

\section{Results and discussion}

\subsection{SSA characterization}

Table 1 gives the concentrations of the major elements (\% of DM) and of the heavy metals of concern (mg/kg DM) in the SSA samples as function of the incineration temperature. This table shows that the $\mathrm{P}$ concentration in the SSA remained almost constant with increasing incineration temperature $(6.65-6.89 \%$ of DM), which was to be expected since $\mathrm{P}$ is not volatilized during incineration [20,32]. Furthermore, Table 1 shows that the concentration of most elements in the SSA was slightly lower in the sample obtained at $550{ }^{\circ} \mathrm{C}$ compared to higher incineration temperatures. This might be explained by the presence of a small amount of carbonates diluting the other elements in the SSA obtained at $550{ }^{\circ} \mathrm{C}$. Indeed, whereas temperatures below $600{ }^{\circ} \mathrm{C}$ merely cause the oxidation of organic compounds, temperatures above $600{ }^{\circ} \mathrm{C}$ also result in the decomposition of inorganic compounds such as carbonates [3,33]. XRD analysis (see Figure 1.a) confirmed that no carbonates were present in the crystalline phase of the SSA samples obtained at incineration temperatures above $650{ }^{\circ} \mathrm{C}$. 
Table 1 Elemental composition of the SSA samples obtained at different incineration temperatures (\% of DM or mg/kg DM).

\begin{tabular}{|c|c|c|c|c|c|c|c|c|c|c|c|}
\hline & \multicolumn{10}{|c|}{ Temperature $\left({ }^{\circ} \mathrm{C}\right)$} \\
\hline & & 550 & 650 & 750 & 800 & 825 & 850 & 875 & 900 & 1000 & 1100 \\
\hline $\mathrm{Al}$ & $(\%$ of DM) & 6.01 & 6.21 & 6.19 & 6.26 & 6.25 & 6.20 & 6.26 & 6.20 & 6.29 & 6.30 \\
\hline $\mathrm{Ca}$ & $(\%$ of DM) & 5.45 & 5.59 & 5.50 & 5.64 & 5.76 & 5.63 & 5.61 & 5.61 & 5.56 & 5.62 \\
\hline $\mathrm{Fe}$ & $(\%$ of $\mathrm{DM})$ & 9.67 & 9.97 & 10.04 & 9.86 & 10.04 & 10.06 & 10.09 & 10.04 & 10.07 & 10.04 \\
\hline $\mathrm{K}$ & $(\%$ of $\mathrm{DM})$ & 1.94 & 2.01 & 1.98 & 2.01 & 2.02 & 2.02 & 2.02 & 1.98 & 2.00 & 2.01 \\
\hline $\mathrm{Mg}$ & $(\%$ of DM) & 1.24 & 1.29 & 1.29 & 1.28 & 1.30 & 1.30 & 1.32 & 1.29 & 1.31 & 1.30 \\
\hline $\mathrm{Na}$ & $(\%$ of DM) & 0.34 & 0.35 & 0.36 & 0.34 & 0.35 & 0.35 & 0.35 & 0.35 & 0.38 & 0.39 \\
\hline $\mathrm{P}$ & $(\%$ of $\mathrm{DM})$ & 6.65 & 6.78 & 6.82 & 6.85 & 6.82 & 6.83 & 6.81 & 6.89 & 6.88 & 6.83 \\
\hline $\mathrm{S}$ & $(\%$ of $\mathrm{DM})$ & 0.50 & 0.49 & 0.43 & 0.36 & 0.29 & 0.25 & 0.19 & 0.14 & 0.03 & 0.02 \\
\hline $\mathrm{Si}$ & (\% of DM) & 18.79 & 19.19 & 19.16 & 19.22 & 19.58 & 19.56 & 19.33 & 19.42 & 19.35 & 19.05 \\
\hline $\mathrm{Ti}$ & (\% of DM) & 0.37 & 0.37 & 0.37 & 0.37 & 0.37 & 0.38 & 0.38 & 0.38 & 0.38 & 0.38 \\
\hline $\mathrm{Cd}$ & $(\mathrm{mg} / \mathrm{kg} \mathrm{DM})$ & 8.3 & 8.7 & 8.5 & 7.9 & 7.7 & 7.4 & 7.5 & 7.7 & 7.2 & 7.5 \\
\hline $\mathrm{Cr}$ & $(\mathrm{mg} / \mathrm{kg} \mathrm{DM})$ & 139 & 141 & 138 & 144 & 145 & 148 & 147 & 145 & 146 & 156 \\
\hline $\mathrm{Cu}$ & $(\mathrm{mg} / \mathrm{kg} \mathrm{DM})$ & 582 & 592 & 598 & 603 & 603 & 605 & 609 & 608 & 605 & 587 \\
\hline $\mathrm{Ni}$ & $(\mathrm{mg} / \mathrm{kg} \mathrm{DM})$ & 60 & 61 & 58 & 57 & 59 & 66 & 62 & 59 & 61 & 63 \\
\hline $\mathrm{Pb}$ & $(\mathrm{mg} / \mathrm{kg} \mathrm{DM})$ & 156 & 160 & 159 & 159 & 157 & 157 & 151 & 147 & 107 & 120 \\
\hline $\mathrm{Zn}$ & $(\mathrm{mg} / \mathrm{kg} \mathrm{DM})$ & 2114 & 2177 & 2151 & 2129 & 2147 & 2169 & 2161 & 2175 & 2042 & 2124 \\
\hline
\end{tabular}

Several authors found that the release of alkali and alkaline earth metals (specifically $\mathrm{Ca}, \mathrm{K}, \mathrm{Mg}$ and $\mathrm{Na}$ ) from biomass fuels in general increases with increasing incineration temperature [34-37]. Yet, in this work, the $\mathrm{Ca}, \mathrm{K}, \mathrm{Mg}$ and $\mathrm{Na}$ concentration in the SSA remained relatively constant with increasing incineration temperature $(5.45-5.76 \%$ of DM, 1.94 $-2.02 \%$ of DM, $1.24-1.32 \%$ of DM and $0.34-0.39 \%$ of DM for a temperature increase from 550 to $1100{ }^{\circ} \mathrm{C}$, respectively). This is related to the high concentration of Si in the SS and hence also in the SSA (18.79-19.58\% of DM), retaining Ca, K, $\mathrm{Mg}$ and $\mathrm{Na}$ in the silicate fraction [34-37]. XRD analysis (see Figure 1.d) indeed showed that these alkali and alkaline earth metals are bound in the silicate fraction as diopside $\left(\mathrm{CaMgSi}_{2} \mathrm{O}_{6}\right)$, microcline $\left(\mathrm{KAlSi}_{3} \mathrm{O}_{8}\right)$, muscovite $\left(\mathrm{KAl}_{3} \mathrm{Si}_{3} \mathrm{O}_{10}(\mathrm{OH}, \mathrm{F})_{2}\right)$, plagioclase $\left((\mathrm{Na}, \mathrm{Ca})(\mathrm{Si}, \mathrm{Al})_{4} \mathrm{O}_{8}\right)$ and smectite-related minerals (e.g., $\left.(\mathrm{Na}, \mathrm{Ca})_{0.3}(\mathrm{Al}, \mathrm{Mg})_{2} \mathrm{Si}_{4} \mathrm{O}_{10}(\mathrm{OH})_{2} \cdot \mathrm{xH}_{2} \mathrm{O}\right)$, all having high boiling points. Table 1 also shows that in general the concentration of most major elements increased very slightly with increasing incineration temperature, which is related to a slight increase in incineration loss with increasing incineration temperature. This increasing incineration loss may reflect the losses of sulfates, chlorides (not measured in this research), oxides and other compounds with low boiling points [32]. Indeed, unlike all other major elements, the concentration of $\mathrm{S}$ in SSA decreased with increasing incineration temperature (from 0.50 to $0.02 \%$ of DM for a temperature increase from 550 to $1100{ }^{\circ} \mathrm{C}$, respectively). Knudsen et al. [34] found that the release of $\mathrm{S}$ at high temperatures is highly influenced by the Si content in incinerated waste samples. For Si-rich waste samples, such as the SS investigated in this research, the alkali and alkaline earth metals originally bound in sulfates are more likely to be incorporated into (alumino-)silicates with increasing incineration temperature, in this way releasing the $\mathrm{S}$ as sulfur dioxide $\left(\mathrm{SO}_{2}\right)$ gas $[34,38,39]$.

Table 1 also shows that the concentration of the heavy metals of concern, except $\mathrm{Pb}$, remained almost constant with increasing incineration temperature (respectively, $7.2-8.7 \mathrm{mg} / \mathrm{kg} \mathrm{DM}$ for Cd, $138-156 \mathrm{mg} / \mathrm{kg} \mathrm{DM} \mathrm{for} \mathrm{Cr,} 582-609 \mathrm{mg} / \mathrm{kg}$ $\mathrm{DM}$ for $\mathrm{Cu}, 57-66 \mathrm{mg} / \mathrm{kg} \mathrm{DM}$ for Ni and $2042-2177 \mathrm{mg} / \mathrm{kg} \mathrm{DM}$ for $\mathrm{Zn}$ ). Previous research showed that retention of heavy metals in SSA is related to high contents of $\mathrm{Si}, \mathrm{Al}$ and $\mathrm{Ca}$. In this case, heavy metals are likely to be incorporated into silicates and aluminates impeding their volatilization $[35,40-46]$. $\mathrm{Pb}$ is the only heavy metal for which the concentration in the SSA decreased at temperatures above $900{ }^{\circ} \mathrm{C}$ (see Table 1), which might be related to $\mathrm{Pb}$ volatilization $[35,41,46,47]$.

\subsection{SSA mineralogy}

XRD analysis (see Figure 1) showed that the major minerals present in the crystalline phase of the SSA samples were quartz $\left(\mathrm{SiO}_{2}\right)$, whitlockite $\left(\mathrm{Ca} 9(\mathrm{Mg}, \mathrm{Fe})\left(\mathrm{PO}_{4}\right)_{6}\left(\mathrm{PO}_{3} \mathrm{OH}\right)\right)$, hematite $\left(\mathrm{Fe}_{2} \mathrm{O}_{3}\right)$ and smectite-related minerals. Furthermore, Figure 1.f shows that the SSA samples contained a large amorphous fraction (26-48\% of DM), of which the mineralogy could not be determined by XRD analysis. Between 550 and $650{ }^{\circ} \mathrm{C}$, there was a decrease in the amount of amorphous fraction, after which it remained more or less constant between 650 and $900{ }^{\circ} \mathrm{C}$. At temperatures above $900{ }^{\circ} \mathrm{C}$, the amount of amorphous fraction started to increase again since higher incineration temperatures imply more glassy SSA due to agglomeration caused by silicate melting [37,48-51]. Unfortunately, the mineralogy of the heavy metals could not be detected by XRD analysis because of their low concentrations in the SSA samples $[45,46]$.

With increasing incineration temperature, in general the amount of hematite, stanfieldite $\left(\mathrm{Ca}_{4}(\mathrm{Mg}, \mathrm{Fe}, \mathrm{Mn})_{5}\left(\mathrm{PO}_{4}\right)_{6}\right)$, whitlockite and microcline in the crystalline phase of the SSA samples increased, whereas the amount of $\mathrm{Mg}-\mathrm{Al}-\mathrm{Fe}-\mathrm{oxide}$ $\left(\mathrm{MgAl}_{0.6} \mathrm{Fe}_{1.4} \mathrm{O}_{4}\right)$ and smectite-related minerals decreased.

According to the XRD analysis, the $\mathrm{P}$ in the crystalline phase of the SSA samples was only present in Ca-phosphates (stanfieldite and whitlockite). However, the results of the SMT protocol showed that a fraction of P in the SSA samples was bound as Al- and/or Fe-phosphates, which was confirmed in the EPMA analysis (see Supplementary Material, Figure S2 $\mathrm{S} 4)$. Since XRD analysis did not detect $\mathrm{Al} / \mathrm{Fe}$-phosphates in the crystalline phase, they were most likely present in the amorphous phase. The literature shows that $\mathrm{Al} / \mathrm{Fe}$-phosphates in the crystalline phase of SSA samples are mainly present in the form of berlinite $\left(\mathrm{AlPO}_{4}\right)$ and iron(III) phosphate $\left(\mathrm{FePO}_{4}\right)[3,7,8,19,52]$. 


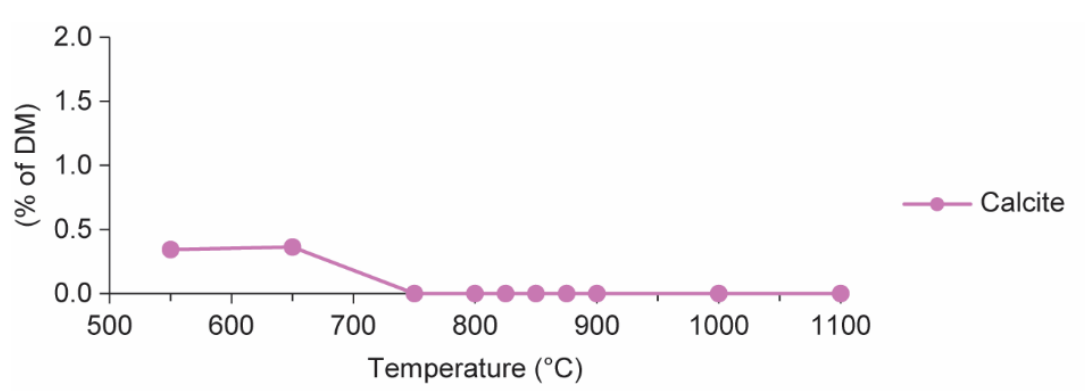

(a) Carbonates

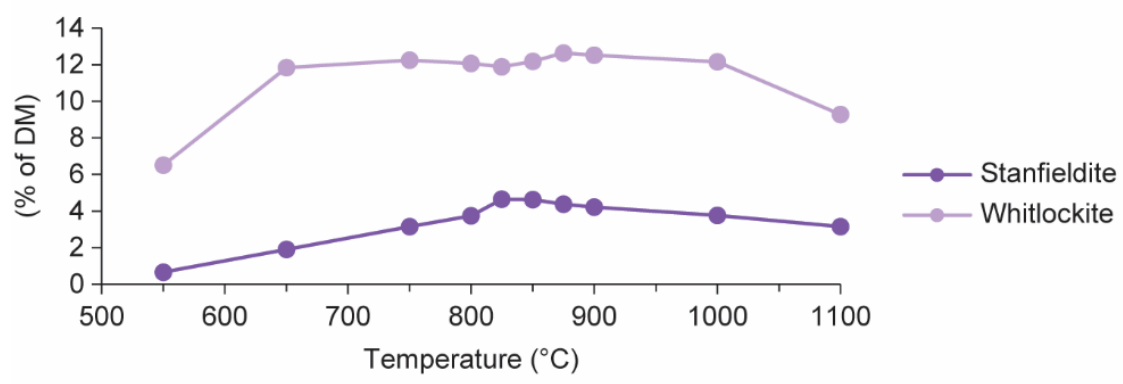

(c) Phosphates

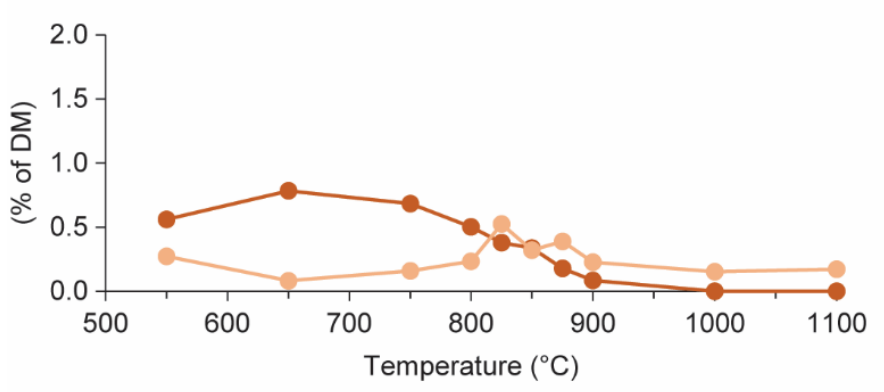

(e) Sulfates

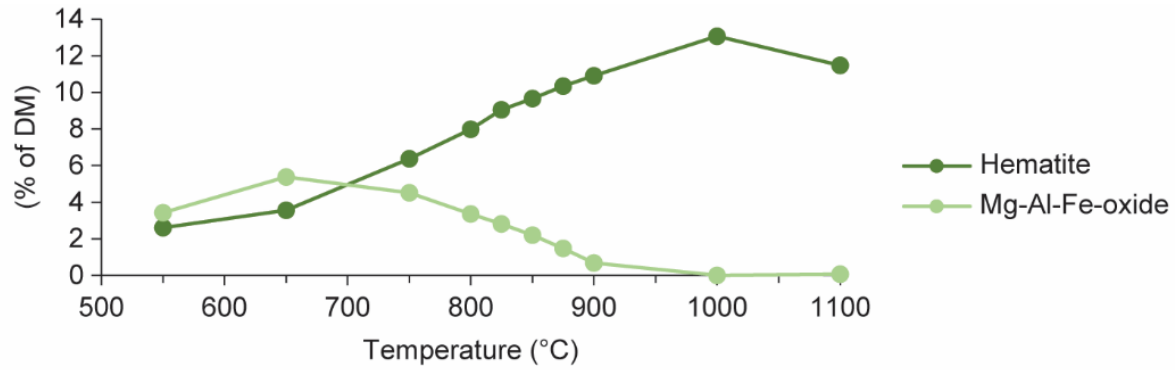

(b) Oxides

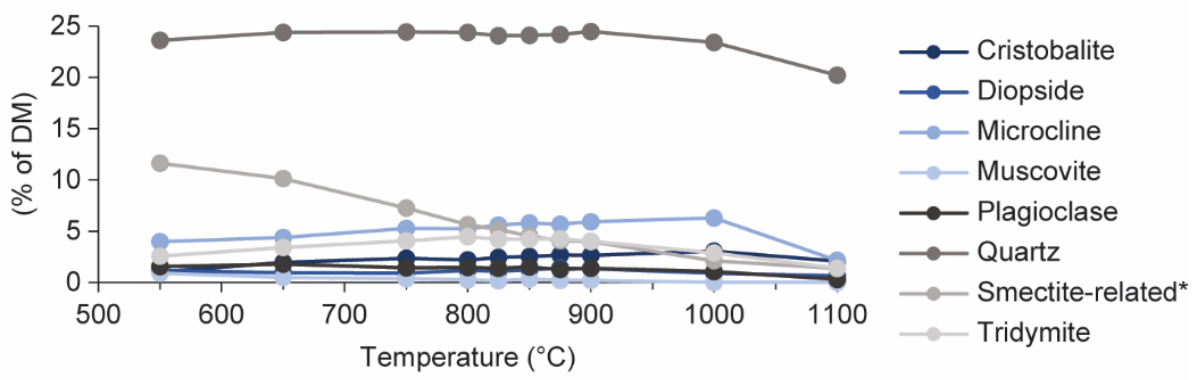

(d) Silicates

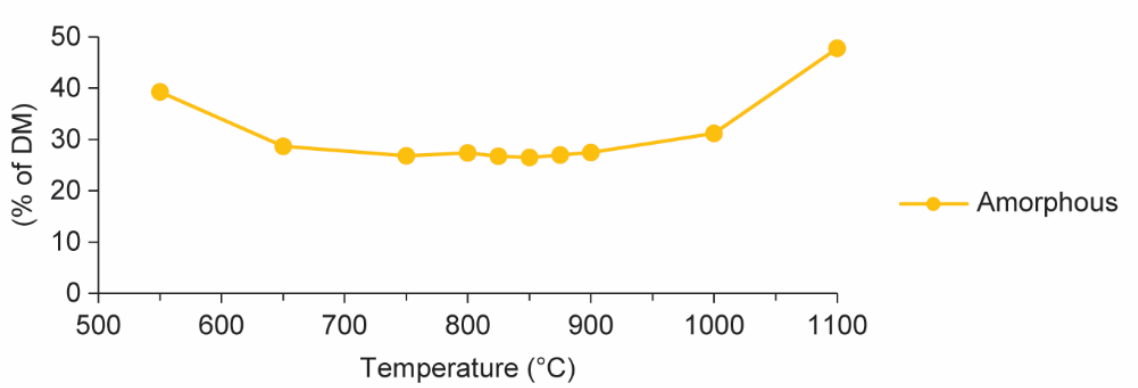

(f) Amorphous phase

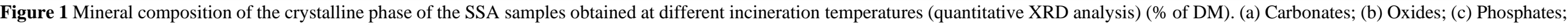
(d) Silicates; (e) Sulfates; (f) Amorphous phase. ${ }^{2}$

* The mineral present is a "heat modified" smectite and it is unclear how closely its composition is related to that of "true" smectite. 
Based on the XRD results (Figure 1), the elemental composition (Table 1) and the results from the SMT protocol, the mass fraction of $\mathrm{P}$ bound in crystalline Ca-phosphates (whitlockite and stanfieldite), in amorphous $\mathrm{Al} / \mathrm{Fe}$-phosphates, and remaining $\mathrm{P}$ of unknown mineralogy in the amorphous phase was calculated as shown in Figure 2. This figure shows that the share of $\mathrm{P}$ bound in crystalline Ca-phosphates increased with increasing incineration temperature to reach a maximum of $51 \%$ at $875^{\circ} \mathrm{C}$, after which it decreased again with increasing incineration temperature. Furthermore, Figure 2 shows that the amount of $\mathrm{P}$ bound in $\mathrm{Al} / \mathrm{Fe}$-phosphates decreased with increasing incineration temperature. The observed conversion of $\mathrm{Al} / \mathrm{Fe}$-phosphates into Ca-phosphates with increasing incineration temperature is in line with previous research [3,1719,23]. This conversion can be explained by reaction of $\mathrm{Al} / \mathrm{Fe}-$ phosphates with $\mathrm{Ca}$ and $\mathrm{Si}$ compounds, forming $\mathrm{Ca}-$ phosphates and acid insoluble hematite, corundum or alumino-silicates [3,8,16,53]. In this work, EPMA showed that at least part of the $\mathrm{P}$ in the SSA sample obtained at $550{ }^{\circ} \mathrm{C}$ consisted of Fe-phosphates (see Supplementary Material, Figure S2). The increasing amount of crystalline hematite in Figure 1.b and the decreasing amount of $\mathrm{P}$ bound in amorphous $\mathrm{Al} / \mathrm{Fe}$ phosphates in Figure 2 confirm that Fe-phosphates were converted into Ca-phosphates and hematite with increasing temperature. Accordingly, the mass fraction of Fe bound in hematite increased from $19 \%$ of total $\mathrm{Fe}$ at $550{ }^{\circ} \mathrm{C}$ up to $91 \%$ of total $\mathrm{Fe}$ at $1000{ }^{\circ} \mathrm{C}$, at which point hardly any $\mathrm{Fe}$-phosphates could be present because almost all Fe was bound in crystalline hematite. On the other hand, the conversion of Al-phosphates into Ca-phosphates and corundum or alumino-silicates could not be observed from the XRD analysis in this work, since between 64 and $94 \%$ of total Al in the SSA samples was bound in the amorphous phase from which the mineralogy is unknown. Yet, extraction data for $\mathrm{Al}$ and Fe as function of the incineration temperature (see Supplementary Material, Figure S5 - S6) showed that the solubility of Al and Fe in sulfuric acid, hydrochloric acid and oxalic acid decreased with increasing incineration temperature. This confirms that with increasing incineration temperature the $\mathrm{Al} / \mathrm{Fe}$-phosphates in the SSA were converted to other $\mathrm{P}$ compounds and $\mathrm{Al}$ and $\mathrm{Fe}$ compounds poorly soluble in acids.

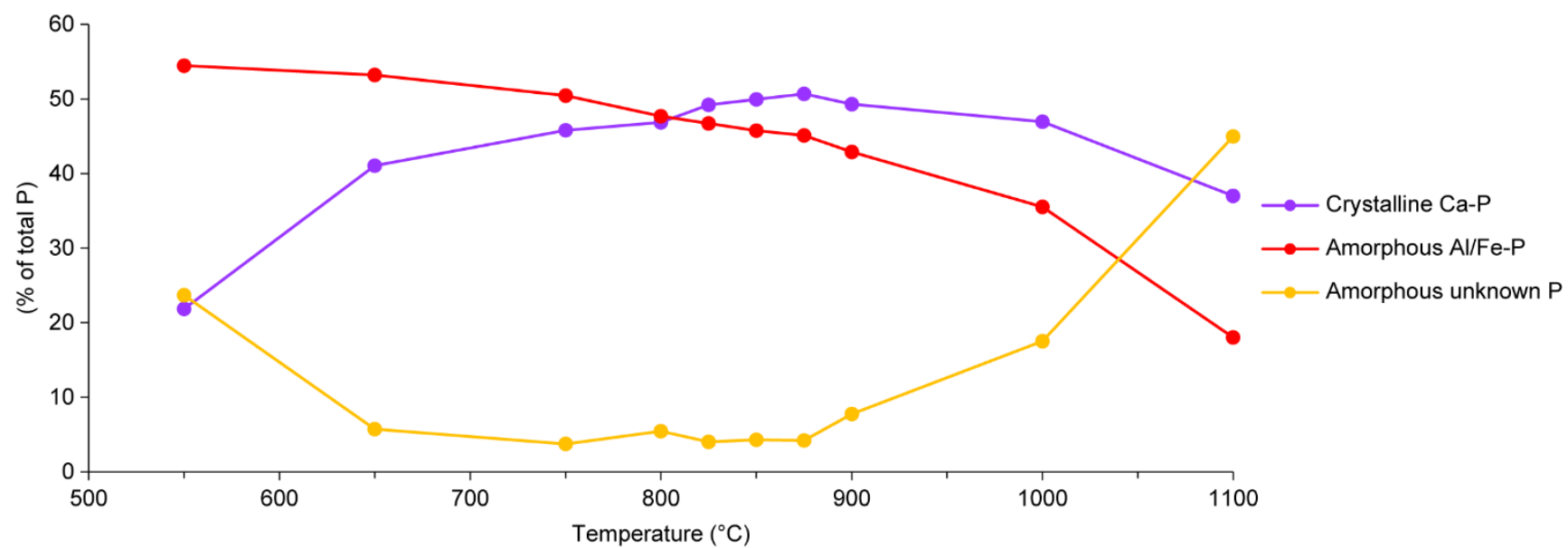

Figure 2 Mass fraction of $\mathrm{P}$ bound in crystalline Ca-phosphates (Ca-P) (whitlockite and stanfieldite), in amorphous $\mathrm{Al} / \mathrm{Fe}-\mathrm{phosphates}$ $(\mathrm{Al} / \mathrm{Fe}-\mathrm{P})$, and remaining $\mathrm{P}$ of unknown mineralogy in the amorphous phase of the SSA samples obtained at different incineration temperatures $(\%$ of total $\mathrm{P})$.

\subsection{Pextraction}

Figure 3 gives the efficiency of P extraction from the SSA samples with sulfuric acid, hydrochloric acid, oxalic acid and sodium hydroxide as function of the incineration temperature. This figure shows that the $\mathrm{P}$ extraction efficiency for sodium hydroxide was lower than for the acidic extraction liquids. Sulfuric acid and hydrochloric acid, both inorganic acids, behaved similarly in terms of $\mathrm{P}$ extraction efficiency as function of the incineration temperature, whereas oxalic acid behaved differently at low $\left(550^{\circ} \mathrm{C}\right)$ and high $\left(1000\right.$ and $\left.1100^{\circ} \mathrm{C}\right)$ incineration temperatures (see Figure 3$)$.

Figure 3 shows that the $\mathrm{P}$ extraction efficiency with sodium hydroxide gradually decreased with increasing incineration temperature, which is related to the decreasing mass fraction of Al/Fe-phosphates in the SSA (see Figure 2). In general, Al- and/or Fe-phosphates dissolve well in alkaline extraction liquids such as sodium hydroxide, whereas Caphosphates do almost not dissolve in alkaline environment [14,30,54,55]. However, the P extraction efficiency with sodium hydroxide was generally lower than the mass fraction of $\mathrm{Al} / \mathrm{Fe}$-phosphates in the SSA samples obtained from the SMT protocol. The Al/Fe-phosphates mass fraction in the SSA samples decreased from 54 to $18 \%$ of total P (see Figure 2) over the considered temperature range, whereas the $\mathrm{P}$ extraction efficiency for sodium hydroxide decreased from 46 to $5 \%$ of total $\mathrm{P}$ (see Figure 3). Hence, a sodium hydroxide concentration higher than $0.5 \mathrm{~N}$, an $\mathrm{L} / \mathrm{S}$ ratio higher than $50 \mathrm{ml} / \mathrm{g}$ ash and/or a contact time longer than $2 \mathrm{~h}$ is required to extract all $\mathrm{Al} / \mathrm{Fe}$-phosphates from the SSA samples. This will, however, undesirably increase the extraction costs while still only a maximum of $54 \%$ of total $\mathrm{P}$ will be extracted, making the economic viability of $\mathrm{P}$ extraction with sodium hydroxide rather doubtful. In this regard, it seems interesting to investigate whether the addition of certain chemicals during the incineration process might shift the $\mathrm{P}$ mineralogy towards more Al/Fe-phosphates in the SSA, in this way increasing the P extraction efficiency for sodium hydroxide extraction. An interesting aspect of $\mathrm{P}$ extraction with sodium hydroxide is that the heavy metal co-extraction is relatively low $[13,29,30]$, resulting in less elaborate extract purification, which in its turn might offset the costs of the chemical addition necessary to increase the share of $\mathrm{Al} / \mathrm{Fe}$ phosphates. 


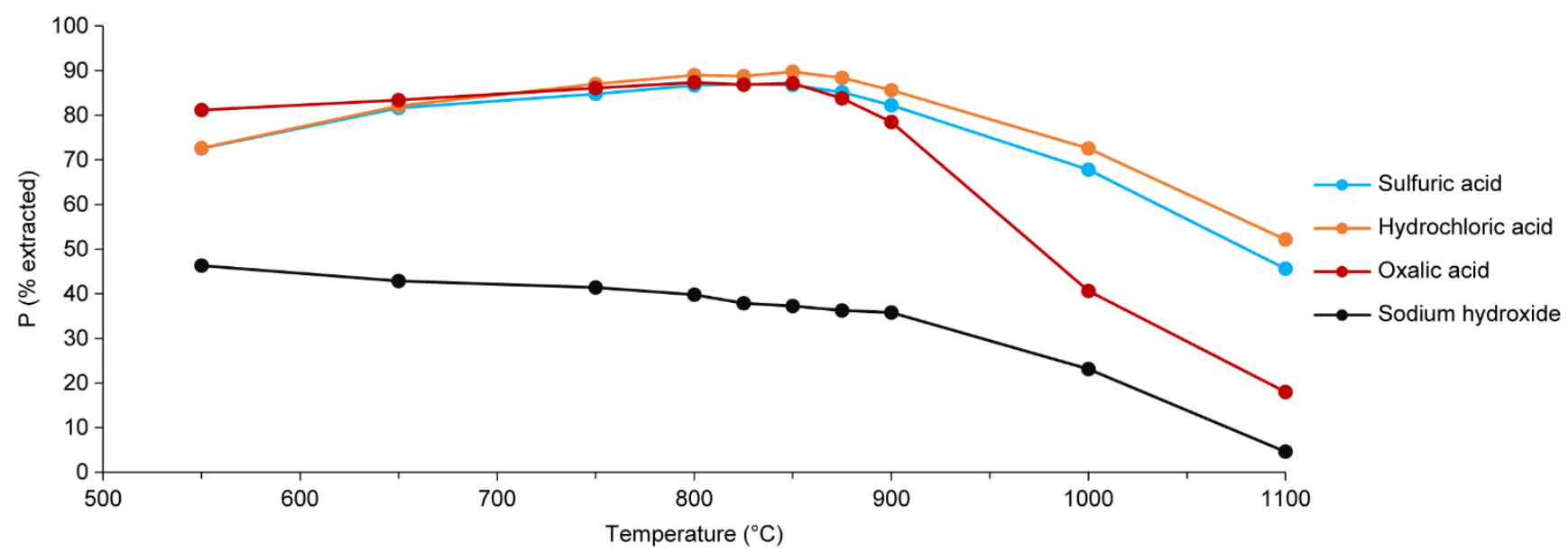

Figure 3 Efficiency of P extraction from the SSA samples obtained at different incineration temperatures (\%). Extraction with sulfuric acid, hydrochloric acid and oxalic acid was performed with an L/S ratio of $10 \mathrm{ml} / \mathrm{g}$ ash, whereas extraction with sodium hydroxide was performed with an $\mathrm{L} / \mathrm{S}$ ratio of $50 \mathrm{ml} / \mathrm{g}$ ash.

For sulfuric acid and hydrochloric acid, Figure 3 shows a parabolic correlation between the P extraction efficiency and the incineration temperature, with a maximum $\mathrm{P}$ extraction efficiency obtained around $850{ }^{\circ} \mathrm{C}(>86 \% \mathrm{P}$ extracted). The increasing $\mathrm{P}$ extraction efficiency between 550 and $850{ }^{\circ} \mathrm{C}$ could be related to the decreasing mass fraction of $\mathrm{P}$ bound as $\mathrm{A} 1 / \mathrm{Fe}$-phosphates in this temperature range (Figure 2). According to the EPMA results, at least part of the P in the SSA sample obtained at $550{ }^{\circ} \mathrm{C}$ was bound as Fe-phosphates (see Supplementary Material, Figure S2). However, it is unknown whether this $\mathrm{P}$ was bound as iron(III) phosphate $\left(\mathrm{FePO}_{4}\right)$, iron(II) phosphate $\left(\mathrm{Fe}_{3}\left(\mathrm{PO}_{4}\right)_{2}\right)$ or other Fe-phosphates. Yet, this information is crucial to explain the $\mathrm{P}$ extraction trend because these Fe-phosphates show different behavior upon acid extraction. Iron(III) phosphate, for instance, is poorly soluble in acidic environment, whereas this is the opposite for iron(II) phosphate $(\mathrm{pH}<2)$ (data from Visual MINTEQ and Levlin and Hultman [56]). Accordingly, if some of the Fe-phosphates in the SSA sample obtained at $550{ }^{\circ} \mathrm{C}$ consisted of iron(III) phosphate (which was previously detected in SSA samples by Liang et al. [3] and Atienza-Martinez et al. [8]), this would explain the somewhat lower P extraction with sulfuric acid and hydrochloric acid from this SSA sample. Increasing the incineration temperature would shift the P bound in this iron(III) phosphate towards Ca-phosphates, as previously discussed in section $3.2[3,8,16]$, resulting in higher $\mathrm{P}$ extraction efficiencies since Ca-phosphates are generally well soluble in acids $[3,30]$.

Furthermore, in Figure 3, it can be seen that the $\mathrm{P}$ extraction efficiency with oxalic acid remained relatively constant for SSA samples obtained between 550 and $850{ }^{\circ} \mathrm{C}$, whereas it slightly increased with sulfuric acid and hydrochloric acid. This can be related to the decrease in organic bound P from 10 to 5\% of total P in the SSA in this temperature range (shown by the results of the SMT protocol). Organic bound P can exist, for instance, in the form of orthophosphate mono- or diesters, which also occur in SS [3,22,57]. Szögi et al. [58] showed that both inorganic acids and (strong) organic acids can easily dissolve inorganic bound $\mathrm{P}$, whereas (strong) organic acids can more easily dissolve organic bound $\mathrm{P}$ compared to inorganic acids.

For the acidic extraction liquids, the $\mathrm{P}$ extraction efficiency decreased with increasing incineration temperature above $850{ }^{\circ} \mathrm{C}$ (see Figure 3). This decreasing $\mathrm{P}$ extraction efficiency is related to the formation of agglomerates caused by silicate melting $[3,8,48,59]$. At incineration temperatures up to $850{ }^{\circ} \mathrm{C}$, the SSA samples were rather brittle and could be ground easily into fine powders. In contrast, the SSA sample obtained at $1000{ }^{\circ} \mathrm{C}$ showed some agglomerates and at $1100{ }^{\circ} \mathrm{C}$ the whole SSA sample was agglomerated into hard chunks that were difficult to ground (see pictures in Supplementary Material, Figure S7). These agglomerates complicate the $\mathrm{P}$ extraction since the extraction liquid cannot properly penetrate the agglomerates and therefore cannot react with all P in the SSA $[3,48]$. In this study, however, the SSA samples were ground before extraction, which slightly promoted the acid penetration due to an increase in the solid/liquid contact surface [3,48]. For sulfuric acid and hydrochloric acid, the P extraction efficiency dropped from 87 to $46 \%$ and from 90 to $52 \%$, respectively, in the temperature range of 850 to $1100{ }^{\circ} \mathrm{C}$. In contrast, the decrease in the P extraction efficiency was larger for oxalic acid in the same temperature range, i.e., from 87 to $18 \%$. This is probably related to the fact that oxalic acid $\left(\mathrm{pK}_{\mathrm{a} 1}=1.25, \mathrm{pK}_{\mathrm{a} 2}=\right.$ $4.27)$ is a weaker acid than sulfuric acid $\left(\mathrm{pK}_{\mathrm{a} 1}=-3, \mathrm{pK}_{\mathrm{a} 2}=1.99\right)$ and hydrochloric acid $\left(\mathrm{pK}_{\mathrm{a}}=-7\right)$.

\subsection{Heavy metal extraction}

As previously cited, it is assumed that many of the heavy metals are likely to be incorporated in silicates or aluminates [35,40-42,45,46]. Also in this work, neither XRD nor EPMA analysis could confirm the presence of these heavy metal silicates or aluminates because of their low concentrations in the SSA. Therefore, to explain the trends in heavy metal extraction efficiency as function of the SS incineration temperature, FactSage thermochemical calculations were used to predict the mineralogy of the heavy metals in the SSA. The results of two thermochemical calculations (with and without the selection of solution phases) are given in Supplementary material (Figure S8 - S9). However, FactSage thermochemical calculations have certain limitations: (1) thermodynamic data is lacking for complex phosphates and silicates; (2) only thermodynamics and no kinetics are taken into account; (3) infinite reaction times are assumed; (4) perfect mixing is assumed 
[60-63]. Therefore, the statements below are to be considered as hypotheses based on the FactSage thermochemical calculations and literature data.

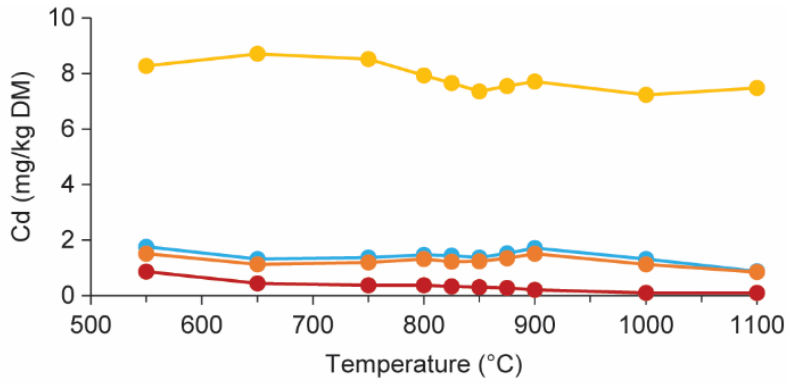

(a) Cd

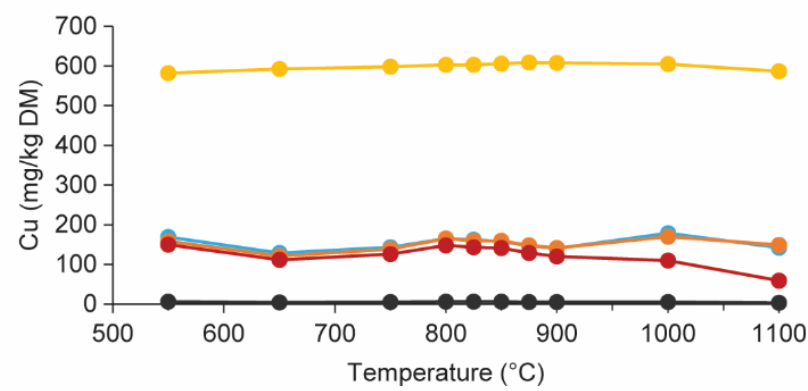

(c) $\mathrm{Cu}$

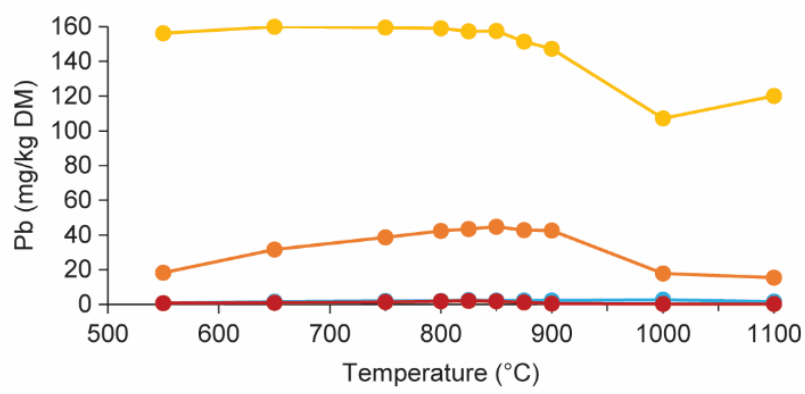

(e) $\mathrm{Pb}$

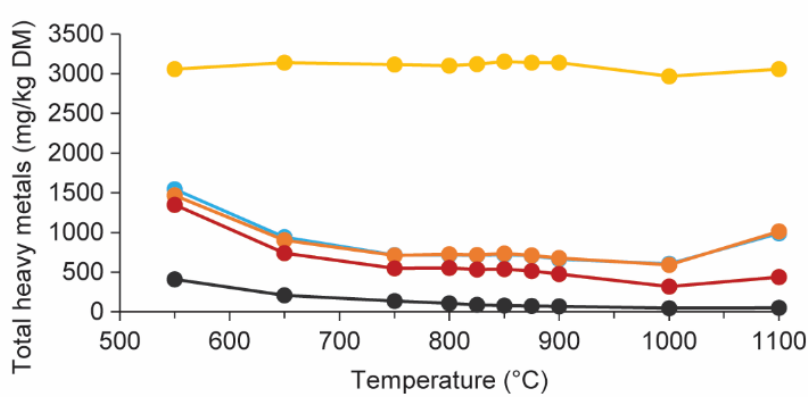

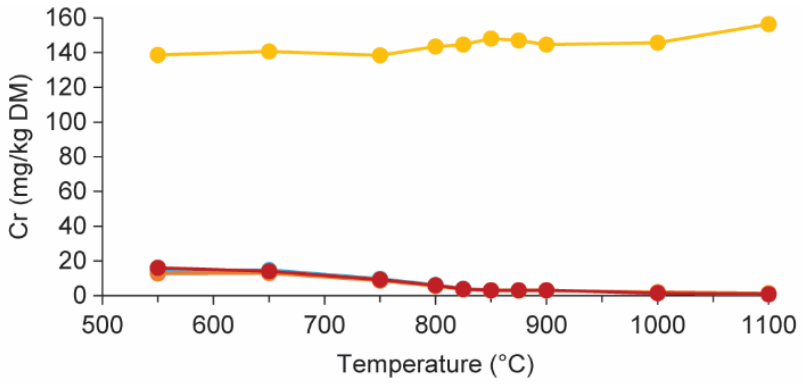

(b) $\mathrm{Cr}$

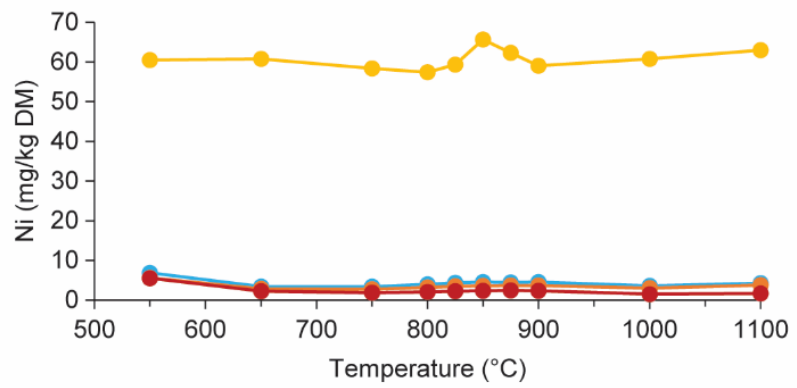

(d) $\mathrm{Ni}$

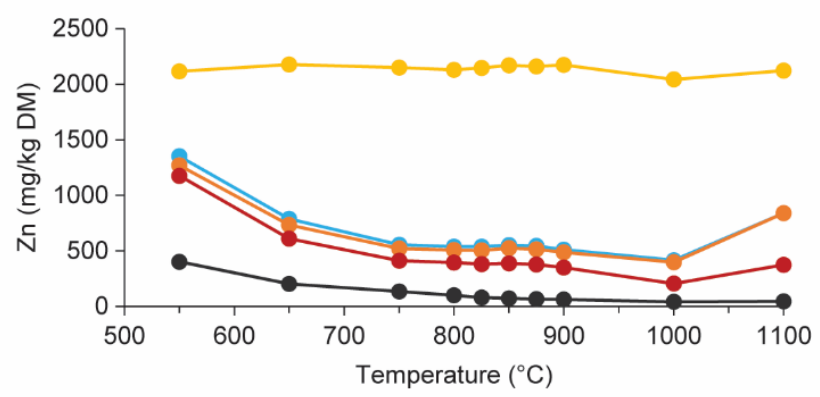

(f) $\mathrm{Zn}$

(g) Total heavy metals

Figure 4 Amount of $\mathrm{Cd}, \mathrm{Cr}, \mathrm{Cu}, \mathrm{Ni}, \mathrm{Pb}$ and $\mathrm{Zn}$ extracted from the $\mathrm{SSA}$ samples obtained at different incineration temperatures (mg/kg DM). Extraction with sulfuric acid, hydrochloric acid and oxalic acid was performed with an L/S ratio of $10 \mathrm{ml} / \mathrm{g}$ ash, whereas extraction with sodium hydroxide was performed with an $\mathrm{L} / \mathrm{S}$ ratio of $50 \mathrm{ml} / \mathrm{g}$ ash. The total amount of $\mathrm{Cd}, \mathrm{Cr}, \mathrm{Cu}, \mathrm{Ni}, \mathrm{Pb}$ and $\mathrm{Zn}$ in the $\mathrm{SSA}$ samples is given by the yellow line (data from Table 1). The sodium hydroxide extraction data for $\mathrm{Cd}, \mathrm{Cr}, \mathrm{Ni}$ and $\mathrm{Pb}$ was below the detection limit value of the ICP-OES measurements and is therefore not given in this figure (for sodium hydroxide extraction $<2.5 \mathrm{mg} / \mathrm{kg} \mathrm{DM}$ for Cd, $\mathrm{Cr}$ and $\mathrm{Ni}$, and < $7.5 \mathrm{mg} / \mathrm{kg} \mathrm{DM}$ for $\mathrm{Pb})$. (a) Cd extraction (mg/kg DM); (b) Cr extraction (mg/kg DM); (c) Cu extraction (mg/kg DM); (d) Ni extraction (mg/kg DM); (e) Pb extraction (mg/kg DM); (f) Zn extraction (mg/kg DM); (g) Total heavy metal extraction (Cd + Cr + $\mathrm{Cu}+\mathrm{Ni}+\mathrm{Pb}+\mathrm{Zn})(\mathrm{mg} / \mathrm{kg} \mathrm{DM})$.

Figure 4 gives the amount of $\mathrm{Cd}, \mathrm{Cr}, \mathrm{Cu}, \mathrm{Ni}, \mathrm{Pb}$ and $\mathrm{Zn}$ extracted from the SSA samples with sulfuric acid, hydrochloric acid, oxalic acid and sodium hydroxide as function of the incineration temperature. No data is given on the sodium hydroxide extraction for $\mathrm{Cd}, \mathrm{Cr}, \mathrm{Ni}$ and $\mathrm{Pb}$ since the concentrations in the extracts were below the ICP-OES detection limits (which was for the sodium hydroxide extraction liquid $<2.5 \mathrm{mg} / \mathrm{kg}$ ash for $\mathrm{Cd}$, $\mathrm{Cr}$ and $\mathrm{Ni}$, and $<7.5 \mathrm{mg} / \mathrm{kg}$ ash for $\mathrm{Pb}$ ). In general, it can be concluded that sulfuric acid and hydrochloric acid resulted in the highest heavy metal extraction, whereas oxalic acid resulted in a slightly lower extraction for most of the heavy metals. Extraction with sodium hydroxide resulted in the lowest heavy metal extraction, which can be explained by the fact that most heavy metal compounds show 
low solubility in alkaline environment $[29,30,64]$. The heavy metal extraction for the acidic extraction liquids is discussed more in detail in the following paragraphs.

Only small amounts of Cd were extracted from all SSA samples, ranging between 0.1 and $1.8 \mathrm{mg} / \mathrm{kg}$ DM (see Figure 4.a). According to the thermochemical calculations, Cd in the SSA is mainly bound by silicates or titanates. These minerals are in general poorly soluble, which is sustained by the fact that maximum $3 \%$ of all $\mathrm{Si}$ and maximum $2 \%$ of all $\mathrm{Ti}$ was extracted from the SSA samples in this work (data not shown). Studies by Pazos et al. [65] and Xiao et al. [66] also showed, by means of sequential extraction experiments, that $>80 \%$ of $\mathrm{Cd}$ in SSA is bound in a residual fraction consisting mainly of poorly soluble (alumino-)silicates. According to the thermochemical calculations, Cd would start to evaporate at temperatures above $800{ }^{\circ} \mathrm{C}$ and would be completely evaporated at temperatures above $1000{ }^{\circ} \mathrm{C}$. However, the lab scale experiments in this work showed Cd stabilization in the SSA over the whole temperature range (see Figure 4.a). This again confirms the hypothesized formation of stable Cd-silicates or Cd-titanates, retaining the Cd in the SSA [40,45,46,60]. For sulfuric acid and hydrochloric acid, the $\mathrm{Cd}$ extraction remained fairly constant with increasing incineration temperature between 550 and $900{ }^{\circ} \mathrm{C}$. Differently, for oxalic acid, the Cd extraction decreased with increasing incineration temperature in this temperature range. For all three extraction liquids, the decrease above $900{ }^{\circ} \mathrm{C}$ might be related to the formation of SSA agglomerates (see last paragraph in section 3.3). Furthermore, Figure 4.a shows that the Cd extraction was lower for oxalic acid compared to sulfuric acid and hydrochloric acid, which might be related to the formation of poorly soluble cadmium oxalate $\left(\mathrm{CdC}_{2} \mathrm{O}_{4}\right)\left(\mathrm{K}_{\mathrm{sp}}=1.42 \times 10^{-8}\right)$.

Figure 4.b shows that the amount of $\mathrm{Cr}$ extracted was relatively low $(<16 \mathrm{mg} / \mathrm{kg} \mathrm{DM})$ and that it decreased with increasing incineration temperature. According to the thermochemical calculations, soluble calcium chromate $\left(\mathrm{CaCrO}_{4}\right)$ occurs in SSA obtained at $550{ }^{\circ} \mathrm{C}$, whereas at higher temperatures, the $\mathrm{Cr}$ mainly occurs as less soluble chromium oxide $\left(\mathrm{Cr}_{2} \mathrm{O}_{3}\right)$ or bound in a molten slag phase. The thermochemical calculations show a sudden mineralogy change from chromate to oxide at $580{ }^{\circ} \mathrm{C}$, while Figure $4 . \mathrm{b}$ rather shows a steady decrease in the $\mathrm{Cr}$ extraction between 550 and $850{ }^{\circ} \mathrm{C}$. It is therefore difficult to link the lab experiments to the sudden mineralogy change predicted by the thermochemical calculations. Verbinnen et al. [67] reported a similar decrease when leaching $\mathrm{Cr}$ with water from contaminated sludge incinerated at temperatures ranging between 400 and $900{ }^{\circ} \mathrm{C}$. They suggested that the highly soluble chromates present at low temperatures will start to form a silicate melt as the incineration temperature increases, in this way preventing the Cr from leaching [67].

The $\mathrm{Cu}$ extraction with sulfuric acid and hydrochloric acid fluctuated slightly with increasing incineration temperature (see Figure 4.c), ranging between 120 and $180 \mathrm{mg} / \mathrm{kg} \mathrm{DM}$. The $\mathrm{Cu}$ extraction with oxalic acid also fluctuated slightly in the SS incineration temperature range of 550 to $1000^{\circ} \mathrm{C}(110-150 \mathrm{mg} / \mathrm{kg} \mathrm{DM})$ and then clearly decreased from $110 \mathrm{mg} / \mathrm{kg} \mathrm{DM}\left(1000^{\circ} \mathrm{C}\right)$ to $59 \mathrm{mg} / \mathrm{kg} \mathrm{DM}\left(1100^{\circ} \mathrm{C}\right)$. The $\mathrm{Cu}$ extraction with sodium hydroxide was much lower than with the acids, ranging between 2.9 and $6.2 \mathrm{mg} / \mathrm{kg}$ DM. The thermochemical calculations show that up to temperatures of 800 ${ }^{\circ} \mathrm{C}$, all $\mathrm{Cu}$ is bound to ferrite $\left(\mathrm{CuFe}_{2} \mathrm{O}_{4}\right)$, which is confirmed by research from Cai et al. [45] and Fraissler et al. [60]. Furthermore, the thermochemical calculations show that at temperatures above $800{ }^{\circ} \mathrm{C}$, the fraction of $\mathrm{Cu}$ bound to ferrite decreases whereas the fraction of $\mathrm{Cu}$ bound in a molten slag phase increases up to $100 \%$ at temperatures above $875{ }^{\circ} \mathrm{C}$. In contrast to the thermochemical calculations, heavy metal sequential extraction experiments for different SSA samples by Latosińska and Czapik [68], J. Li et al. [64,69], Li et al. [70], Pazos et al. [65] and Xiao et al. [66] showed only between 0.5 and $15 \%$ of total $\mathrm{Cu}$ bound to $\mathrm{Fe}$ - or Mn-oxides. In their research, they divided the heavy metal minerals into four fractions: (1) acid soluble/exchangeable fraction (metals bound to carbonates); (2) reducible fraction (metals bound to Fe and Mnoxides); (3) oxidizable fraction (metals bound with organic matter or occurring in the form of sulfides); (4) residual fraction (metals bound with (alumino-)silicates). The oxidizable and residual fraction are considered to be rather stable and immobile. They found that between 55 and $90 \%$ of all $\mathrm{Cu}$ in SSA occurred in the residual fraction and was hence bound with for instance (alumino-)silicates. Moreover, between 8 and $40 \%$ of all $\mathrm{Cu}$ occurred in organic or sulfide bounds (oxidizable fraction). From their research, it could be concluded that most of the $\mathrm{Cu}(>80 \%)$ in SSA was bound in the immobile fractions [64-66,68-70]. Research by J. Li et al. [69] demonstrated that small amounts of these immobile fractions still dissolved upon extraction with sulfuric acid and oxalic acid (no hydrochloric acid used in their experiments). Furthermore, they showed that the $\mathrm{Cu}$ in the reducible fraction almost completely dissolved upon extraction with sulfuric acid and oxalic acid. However, it should be noted that the sulfuric acid and oxalic acid concentrations used by J. Li et al. [69] were twice as high as in this work, which affects the extraction efficiency of the heavy metals [3,13]. In this work, between 20 and $30 \%$ of all Cu was extracted with sulfuric acid and hydrochloric acid, while this was between 10 and $26 \%$ with oxalic acid. Hence, following the results from $\mathrm{J}$. Li et al. [69], it is assumed that only a small fraction of $\mathrm{Cu}$-ferrite was present in the SSA samples which was completely dissolving upon extraction, whereas the rest of the $\mathrm{Cu}$ occurred in poorly soluble compounds such as (alumino-)silicates or sulfides.

Figure 4.d shows that the amount of $\mathrm{Ni}$ extracted was $<7 \mathrm{mg} / \mathrm{kg}$ DM over the full temperature range. Furthermore, from Figure 4.d it is clear that the incineration temperature had little effect on the Ni extraction, except for the slight decrease between 550 and $650{ }^{\circ} \mathrm{C}$. However, the thermochemical calculations reveal no difference in Ni mineralogy for SSA samples at 550 and $650{ }^{\circ} \mathrm{C}$ that can explain this slight decrease. The thermochemical calculations show that all $\mathrm{Ni}$ is bound by silicates, titanates or aluminate and ferrite spinels and with increasing incineration temperature above $850{ }^{\circ} \mathrm{C}$, an increasing share of $\mathrm{Ni}$ is incorporated into a molten slag phase. The binding of Ni in ferrite spinel in SSA was previously discussed in a study of Fraissler et al. [60], whereas the binding of $\mathrm{Ni}$ in silicates was previously discussed in a study of Cai et al. [45]. Silicates, titanates and ferrite and aluminate spinels were shown to immobilize $\mathrm{Ni}$, in this way preventing the $\mathrm{Ni}$ from extracting [45,71]. This is confirmed by sequential extraction experiments showing that a substantial fraction of Ni in SSA is bound in an immobile fraction [64,66,68,69].

For $\mathrm{Pb}$, there was a substantial difference between extraction with hydrochloric acid and extraction with sulfuric acid or oxalic acid (see Figure 4.e). The low Pb extraction with sulfuric acid and oxalic acid ( $3 \mathrm{mg} / \mathrm{kg} \mathrm{DM}) \mathrm{can}$ be explained 
by the formation of poorly soluble lead(II) sulfate $\left(\mathrm{PbSO}_{4}\right)\left(\mathrm{K}_{\mathrm{sp}}=2.53 \times 10^{-8}\right)$ and lead(II) oxalate $\left(\mathrm{PbC}_{2} \mathrm{O}_{4}\right)$ $\left(\mathrm{K}_{\mathrm{sp}}=4.8 \times 10^{-10}\right)$, respectively [72,73]. With hydrochloric acid, the Pb extraction increased from 18 to $45 \mathrm{mg} / \mathrm{kg} \mathrm{DM}$ between 550 and $850{ }^{\circ} \mathrm{C}$, after which it remained fairly constant between 850 and $900{ }^{\circ} \mathrm{C}$, and then decreased again sharply to $15 \mathrm{mg} / \mathrm{kg} \mathrm{DM}$ between 900 and $1100{ }^{\circ} \mathrm{C}$ (see Figure 4.e). The decrease in $\mathrm{Pb}$ extraction between 900 and $1100{ }^{\circ} \mathrm{C}$ has two clear explanations. First, the total amount of $\mathrm{Pb}$ in the SSA samples decreased in this temperature range due to partial $\mathrm{Pb}$ volatilization (yellow line in Figure 4.e) $[41,60]$. Second, agglomerate formation incorporated $\mathrm{Pb}$ in the silicate melt $[35,41,42]$, which showed low solubility (maximum $3 \%$ of all Si extracted in this research). The thermochemical calculations indeed confirm that a molten slag phase is formed at temperatures from around $800{ }^{\circ} \mathrm{C}$. However, the increase in $\mathrm{Pb}$ extraction between 550 and $850{ }^{\circ} \mathrm{C}$ with hydrochloric acid is not so obvious to explain. According to the thermochemical calculations, there are three temperature zones in which the $\mathrm{Pb}$ mineralogy remains relatively constant. Between 550 and $750{ }^{\circ} \mathrm{C}$ all $\mathrm{Pb}$ occurs bound as lead(II) hexaaluminate $\left(\mathrm{PbAl}_{12} \mathrm{O}_{19}\right)$. Furthermore, between 750 and $825{ }^{\circ} \mathrm{C}$ almost all $\mathrm{Pb}$ occurs bound as lead(II) sulfate, whereas between 825 and $1100{ }^{\circ} \mathrm{C}, \mathrm{Pb}$ mainly occurs bound in a molten slag phase with a small amount of $\mathrm{Pb}$ evaporating as gaseous lead(II) oxide $(\mathrm{PbO})$. The extraction data in Figure 4.e show a gradual increase in $\mathrm{Pb}$ extraction, whereas the thermochemical calculations only indicate sudden mineralogy changes around 750 and 825 ${ }^{\circ} \mathrm{C}$, making it difficult to link this quantitatively to the increasing Pb extraction. Besides, in general, lead(II) hexaaluminate, lead(II) sulfate and $\mathrm{Pb}$ bound in a molten slag phase all exhibit poor solubility [74]. Therefore, the mineralogy changes predicted by the thermochemical calculations did not give a clear explanation for the increasing $\mathrm{Pb}$ extraction with increasing temperature.

Of the considered heavy metals, Zn was not only present in the SSA at the highest concentrations but was also extracted to the highest extent (see Figure 4.f). With increasing incineration temperature, Zn extraction showed a decreasing tendency for both acidic extraction and alkaline extraction (see Figure 4.f). This is in line with results found by Liang et al. [3] for acidic extraction. Furthermore, Li et al. [70] found that in SSA obtained at $500{ }^{\circ} \mathrm{C}$, about $60 \%$ of all $\mathrm{Zn}$ showed high mobility and leachability, whereas in SSA obtained at $800{ }^{\circ} \mathrm{C}$, this decreased to about $35 \%$. The increase in $\mathrm{Zn}$ extraction between 1000 and $1100{ }^{\circ} \mathrm{C}$ observed in Figure 4.f was rather unexpected since it was presumed that the formation of agglomerates at $1100{ }^{\circ} \mathrm{C}$ would decrease the $\mathrm{Zn}$ extraction. At temperatures below $1000{ }^{\circ} \mathrm{C}$, the thermochemical calculations show the incorporation of $\mathrm{Zn}$ in a silicate or an aluminate and ferrite spinel phase. Furthermore, the thermochemical calculations show that above $800{ }^{\circ} \mathrm{C}$ a $\mathrm{Zn}$ containing slag phase starts to form, while $\mathrm{Zn}$ mainly occurs in a molten slag phase at temperatures above $1000{ }^{\circ} \mathrm{C}$. The presence of $\mathrm{Zn}$ bound in aluminate spinel, ferrite spinel and silicates in SSA was previously discussed in studies by Cai et al. [45], Fraissler et al. [60], Guo et al. [46], Liu et al. [75] and Nowak et al. [42]. However, aluminate spinels, ferrite spinels and silicates generally show poor solubility, so the results of the thermochemical calculations do not sustain the $\mathrm{Zn}$ extraction trend observed for SSA samples obtained at 550 and $650{ }^{\circ} \mathrm{C}$. Since high $\mathrm{Zn}$ extraction was obtained at 550 and $650{ }^{\circ} \mathrm{C}$, it is hypothesized that some of the $\mathrm{Zn}$ at these temperatures was bound in well soluble compounds such as for instance zinc sulfate $\left(\mathrm{ZnSO}_{4}\right)$ or zinc chloride $\left(\mathrm{ZnCl}_{2}\right)$. At higher temperatures, the $\mathrm{Zn}$ was most likely bound as aluminate spinel, ferrite spinel or silicates as predicted by the thermochemical calculations. This is confirmed by sequential extraction experiments performed by Chen et al. [51], showing an increase in Zn bound in a stable residual fraction with increasing incineration temperature. Furthermore, Figure 4 shows that $\mathrm{Zn}$ was the only heavy metal showing relatively high extraction for sodium hydroxide, which is related to its amphoteric character allowing it to dissolve in both acid and alkaline environment [76].

\subsection{Selection of optimal incineration temperature}

A general conclusion is that higher incineration temperatures immobilized the heavy metals in the SSA, in this way decreasing the heavy metal extraction (see Figure 4). Figure 4.g shows that the total heavy metal extraction was lowest at a SS incineration temperature of $1000^{\circ} \mathrm{C}$. However, at $1000^{\circ} \mathrm{C}$, the $\mathrm{P}$ extraction efficiency was below $73 \%$ due to agglomerate formation (see Figure 3). Hence, if SS would be incinerated at $1000{ }^{\circ} \mathrm{C}$, the heavy metal co-extraction would be minimal, in this way reducing the downstream processing costs for heavy metal removal. However, in this case, more than $27 \%$ of $\mathrm{P}$ is not extracted from the SSA. Therefore, the selection of the optimal incineration temperature will depend on economic considerations such as the trade-off between $\mathrm{P}$ extraction efficiency (affecting the revenue) and heavy metal co-extraction (affecting the downstream processing costs). Hence, combining the data in Figure 3 and Figure 4.g and taking into account the above mentioned economic considerations, it can be concluded that an incineration temperature in the range of 800 to $850{ }^{\circ} \mathrm{C}$ seems most optimal for obtaining sufficiently high $\mathrm{P}$ extraction combined with low co-extraction of heavy metals. In this temperature range, all acidic extraction liquids showed similar P extraction efficiencies (respectively, $87-90 \%$, see Figure 3). In contrast, oxalic acid showed lower co-extraction of heavy metals compared to sulfuric acid and hydrochloric acid (respectively, about $17 \%$ of heavy metals extracted compared to about $23 \%$, see Figure $4 . g$ ). However, from an economic point of view, it might be most interesting to use sulfuric acid because it is cheaper than oxalic acid and hydrochloric acid [13,14,77]. 


\section{Conclusions}

Whereas the total content of P and heavy metals in the SSA remained fairly constant with increasing SS incineration temperature, the extraction of these elements with sulfuric acid, hydrochloric acid, oxalic acid and sodium hydroxide showed considerable variation, which can be related to changes in $\mathrm{P}$ and heavy metal mineralogy:

- Increasing incineration temperature decreased the mass fraction of $\mathrm{P}$ bound in $\mathrm{Al} / \mathrm{Fe}$-phosphates in SSA, in this way decreasing the efficiency of $\mathrm{P}$ extraction with sodium hydroxide.

- The efficiency of P extraction with sulfuric acid, hydrochloric acid and oxalic acid increased in the temperature range $550-850{ }^{\circ} \mathrm{C}$. There are two possible explanations for this: (1) with increasing incineration temperature, iron(III) phosphate, which is poorly soluble in acidic environment, was converted into more soluble Ca-phosphates; (2) with increasing incineration temperature, the fraction of organic bound $\mathrm{P}$ decreased, which increased the $\mathrm{P}$ extraction with the inorganic acids sulfuric acid and hydrochloric acid, but hardly affected the $\mathrm{P}$ extraction with oxalic acid.

- The efficiency of $\mathrm{P}$ extraction with acids decreased in the temperature range $850-1100{ }^{\circ} \mathrm{C}$, which is related to the incorporation of $\mathrm{P}$ into a poorly soluble silicate melt (agglomerate formation).

- Increasing incineration temperature enhanced heavy metal immobilization in the SSA, in this way decreasing the heavy metal co-extraction. SSA obtained at $1000{ }^{\circ} \mathrm{C}$ resulted in lowest total heavy metal co-extraction.

Overall, it can be concluded that incinerating SS between 800 and $850{ }^{\circ} \mathrm{C}$ offers the best compromise between high $\mathrm{P}$ extraction and low heavy metal co-extraction from the obtained SSA. In this temperature range, all acidic extraction liquids showed similar P extraction efficiencies, whereas the heavy metal co-extraction was lowest for oxalic acid.

\section{Suggestions for further research}

The scope of this research was to evaluate the influence of the incineration temperature on the $\mathrm{P}$ and heavy metal extraction from SSA. Further research could also evaluate the influence of chemical addition during the incineration process to examine whether and to which extent this affects the P and heavy metal extraction from SSA. For instance, chemical addition might increase the $\mathrm{Al} / \mathrm{Fe}$-phosphates content of SSA in this way improving the economic viability of sodium hydroxide extraction. Besides, it is interesting to evaluate whether chemical addition affects the immobilization of the heavy metals so that less heavy metals would be co-extracted in acidic environment.

\section{Acknowledgements}

Funding: This work was supported by Fonds Wetenschappelijk Onderzoek Vlaanderen (FWO) (Belgium) [project number $1 \mathrm{~S} 08418 \mathrm{~N}-1 \mathrm{~S} 08420 \mathrm{~N}]$.

Furthermore, we want to thank Aquafin for supplying the SS sample.

\section{Supplementary Material}

See appendix.

\section{References}

[1] U.S. Geological Survey (USGS), Phosphate rock, in: Miner. Commod. Summ. 2020, 2020: pp. $122-123$. https://doi.org/10.3133/mcs2020.

[2] E. Desmidt, K. Ghyselbrecht, Y. Zhang, L. Pinoy, B. Van der Bruggen, W. Verstraete, K. Rabaey, B. Meesschaert, Global phosphorus scarcity and full-scale P-recovery techniques: A review, Crit. Rev. Environ. Sci. Technol. 45 (2015) 336-384. https://doi.org/10.1080/10643389.2013.866531.

[3] S. Liang, H. Chen, X. Zeng, Z. Li, W. Yu, K. Xiao, J. Hu, H. Hou, B. Liu, S. Tao, J. Yang, A comparison between sulfuric acid and oxalic acid leaching with subsequent purification and precipitation for phosphorus recovery from sewage sludge incineration ash, Water Res. 159 (2019) 242-251. https://doi.org/10.1016/j.watres.2019.05.022.

[4] S. Kratz, C. Vogel, C. Adam, Agronomic performance of P recycling fertilizers and methods to predict it: A review, Nutr. Cycl. Agroecosystems. 115 (2019) 1-39. https://doi.org/10.1007/s10705-019-10010-7.

[5] L. Fang, Q. Wang, J. Li, C.S. Poon, C.R. Cheeseman, S. Donatello, D.C.W. Tsang, Feasibility of wet-extraction of phosphorus from incinerated sewage sludge ash (ISSA) for phosphate fertilizer production: A critical review, Crit. Rev. Environ. Sci. Technol. 51 (2021) 939-971. https://doi.org/10.1080/10643389.2020.1740545.

[6] Eurostat, Sewage sludge production and disposal, (2016). https://ec.europa.eu/eurostat/web/productsdatasets/product?code=env_ww_spd (accessed May 13, 2020).

[7] C. Adam, B. Peplinski, M. Michaelis, G. Kley, F.-G. Simon, Thermochemical treatment of sewage sludge ashes for phosphorus recovery, Waste Manag. 29 (2009) 1122-1128. https://doi.org/10.1016/j.wasman.2008.09.011. 
[8] M. Atienza-Martínez, G. Gea, J. Arauzo, S.R.A. Kersten, A.M.J. Kootstra, Phosphorus recovery from sewage sludge char ash, Biomass and Bioenergy. 65 (2014) 42-50. https://doi.org/10.1016/j.biombioe.2014.03.058.

[9] European Sustainable Phosphorus Platform (ESPP), ESPP phosphorus fact sheet, 2019. https://phosphorusplatform.eu/images/download/ESPP-Phosphorus-fact-sheet-v21-4-19.pdf.

[10] L. Fang, J. Li, M.Z. Guo, C.R. Cheeseman, D.C.W. Tsang, S. Donatello, C.S. Poon, Phosphorus recovery and leaching of trace elements from incinerated sewage sludge ash (ISSA), Chemosphere. 193 (2018) $278-287$. https://doi.org/10.1016/j.chemosphere.2017.11.023.

[11] Q. Wang, J. Li, P. Tang, L. Fang, C.S. Poon, Sustainable reclamation of phosphorus from incinerated sewage sludge ash as value-added struvite by chemical extraction, purification and crystallization, J. Clean. Prod. 181 (2018) $717-$ 725. https://doi.org/10.1016/j.jclepro.2018.01.254.

[12] S. Donatello, D. Tong, C.R. Cheeseman, Production of technical grade phosphoric acid from incinerator sewage sludge ash (ISSA), Waste Manag. 30 (2010) 1634-1642. https://doi.org/10.1016/j.wasman.2010.04.009.

[13] L. Luyckx, S. Geerts, J. Van Caneghem, Closing the phosphorus cycle: Multi-criteria techno-economic optimization of phosphorus extraction from wastewater treatment sludge ash, Sci. Total Environ. 713 (2020) 135543. https://doi.org/10.1016/j.scitotenv.2019.135543.

[14] L. Luyckx, D.S. Sousa Correia, J. Van Caneghem, Linking phosphorus extraction from different types of biomass incineration ash to ash mineralogy, ash composition and chemical characteristics of various types of extraction liquids, Waste and Biomass Valorization. 12 (2021) 5235-5248. https://doi.org/10.1007/s12649-021-01368-3.

[15] K. Gorazda, Z. Wzorek, M. Jodko, The influence of thermal processing of sewage sludge on the usage properties of the formed ash, Polish J. Chem. Technol. 9 (2007) 21-27. https://doi.org/10.2478/v10026-007-0083-y.

[16] K. Gorazda, Z. Kowalski, Z. Wzorek, From sewage sludge ash to calcium phosphate fertilizers, Polish J. Chem. Technol. 14 (2012) 54-58. https://doi.org/10.2478/v10026-012-0084-3.

[17] R. Li, W. Teng, Y. Li, W. Wang, R. Cui, T. Yang, Potential recovery of phosphorus during the fluidized bed incineration of sewage sludge, J. Clean. Prod. 140 (2017) 964-970. https://doi.org/10.1016/j.jclepro.2016.06.177.

[18] F. Yang, J. Chen, M. Yang, X. Wang, Y. Sun, Y. Xu, G. Qian, Phosphorus recovery from sewage sludge via incineration with chlorine-based additives, Waste Manag. $95 \quad$ (2019) 644-651. https://doi.org/10.1016/j.wasman.2019.06.029.

[19] R. Li, Z. Zhang, Y. Li, W. Teng, W. Wang, T. Yang, Transformation of apatite phosphorus and non-apatite inorganic phosphorus during incineration of sewage sludge, Chemosphere. $141 \quad$ (2015) 57-61. https://doi.org/10.1016/j.chemosphere.2015.05.094.

[20] H. Xu, H. Zhang, L. Shao, P. He, Fraction distributions of phosphorus in sewage sludge and sludge ash, Waste and Biomass Valorization. 3 (2012) 355-361. https://doi.org/10.1007/s12649-011-9103-5.

[21] B. Peplinski, C. Adam, M. Michaelis, G. Kley, F. Emmerling, F.-G. Simon, Reaction sequences in the thermochemical treatment of sewage sludge ashes revealed by X-ray powder diffraction - A contribution to the European project SUSAN, in: Zeitschrift Für Krist. Suppl. (European Powder Diffr. Conf., September 19-22, Warsaw, Poland, 2009: pp. 459-464. https://doi.org/10.1524/zksu.2009.0068.

[22] T.-T. Qian, H. Jiang, Migration of phosphorus in sewage sludge during different thermal treatment processes, ACS Sustain. Chem. Eng. 2 (2014) 1411-1419. https://doi.org/10.1021/sc400476j.

[23] D. Steckenmesser, C. Vogel, C. Adam, D. Steffens, Effect of various types of thermochemical processing of sewage sludges on phosphorus speciation, solubility, and fertilization performance, Waste Manag. 62 (2017) $194-203$. https://doi.org/10.1016/j.wasman.2017.02.019.

[24] S. Liang, L. Yang, H. Chen, W. Yu, S. Tao, S. Yuan, K. Xiao, J. Hu, H. Hou, B. Liu, J. Yang, Phosphorus recovery from incinerated sewage sludge ash (ISSA) and reutilization of residues for sludge pretreated by different conditioners, Resour. Conserv. Recycl. 169 (2021) 105524. https://doi.org/10.1016/j.resconrec.2021.105524.

[25] W. Ma, Y. Tang, P. Wu, Y. Xia, Sewage sludge incineration ash for coimmobilization of lead, zinc and copper: Mechanisms of metal incorporation and competition, Waste Manag. 99 (2019) $102-111$. https://doi.org/10.1016/j.wasman.2019.08.029.

[26] V. Ruban, J.F. López--Sánchez, P. Pardo, G. Rauret, H. Muntau, P. Quevauviller, Development of a harmonised phosphorus extraction procedure and certification of a sediment reference material, J. Environ. Monit. 3 (2001) 121125. https://doi.org/10.1039/b005672n.

[27] P. Pardo, G. Rauret, J.F. López-Sánchez, Shortened screening method for phosphorus fractionation in sediments: A complementary approach to the standards, measurements and testing harmonised protocol, Anal. Chim. Acta. 508 (2004) 201-206. https://doi.org/10.1016/j.aca.2003.11.005.

[28] S. Donatello, A. Freeman-Pask, M. Tyrer, C.R. Cheeseman, Effect of milling and acid washing on the pozzolanic activity of incinerator sewage sludge ash, Cem. Concr. Compos. 32 (2010) 54-61. https://doi.org/10.1016/j.cemconcomp.2009.09.002.

[29] S. Petzet, B. Peplinski, S.Y. Bodkhe, P. Cornel, Recovery of phosphorus and aluminium from sewage sludge ash by a new wet chemical elution process (SESAL-Phos-recovery process), Water Sci. Technol. 64 (2011) $693-699$. 
https://doi.org/10.2166/wst.2011.682.

[30] E. Levlin, M. Löwén, K. Stark, Phosphorus recovery from sludge incineration ash and supercritical water oxidation residues with use of acid and base, in: Proc. a Polish-Swedish Semin., October 25-28, Wisla, Poland, 2004: pp. 1928.

[31] European Committee for Standardization, EN 13656:2002 Characterization of waste - Microwave assisted digestion with hydrofluoric $(\mathrm{HF})$, nitric $(\mathrm{HNO} 3)$ and hydrochloric $(\mathrm{HCl})$ acid mixture for subsequent determination of elements, (2002).

[32] F.-S. Zhang, S. Yamasaki, M. Nanzyo, Application of waste ashes to agricultural land - Effect of incineration temperature on chemical characteristics, Sci. Total Environ. 264 (2001) 205-214. https://doi.org/10.1016/S00489697(00)00715-4.

[33] C. Vanhoof, K. Tirez, Bepaling van organische stof/koolstof in vaste stoffen, 2003.

[34] J.N. Knudsen, P.A. Jensen, K. Dam-Johansen, Transformation and release to the gas phase of Cl, K, and S during combustion of annual biomass, Energy and Fuels. 18 (2004) 1385-1399. https://doi.org/10.1021/ef049944q.

[35] S.C. van Lith, P.A. Jensen, F.J. Frandsen, P. Glarborg, Release to the gas phase of inorganic elements during wood combustion. Part 2: Influence of fuel composition, Energy and Fuels. 22 (2008) 1598-1609. https://doi.org/10.1021/ef060613i.

[36] Z.-H. Zhang, Q. Song, Q. Yao, R.-M. Yang, Influence of the atmosphere on the transformation of alkali and alkaline earth metallic species during rice straw thermal conversion, Energy and Fuels. 26 (2012) 1892-1899. https://doi.org/10.1021/ef2011645.

[37] X. Wu, Z. Wei, J. Liu, Z. Chen, F. Evrendilek, W. Huang, Oxy-fuel and air combustion performances and gas-toash products of aboveground and belowground biomass of Sedum alfredii Hance, Chem. Eng. J. 422 (2021) 130312. https://doi.org/10.1016/j.cej.2021.130312.

[38] S.C. van Lith, V. Alonso-Ramirez, P.A. Jensen, F.J. Frandsen, P. Glarborg, Release to the gas phase of inorganic elements during wood combustion. Part 1: Development and evaluation of quantification methods, Energy and Fuels. 20 (2006) 964-978. https://doi.org/10.1021/ef050131r.

[39] J. Zhang, J. Chen, J. Liu, W. Xie, F. Evrendilek, W. Li, Coupled mechanisms of reaction kinetics, gas emissions, and ash mineral transformations during combustion of $\mathrm{AlCl} 3$-conditioned textile dyeing sludge, J. Hazard. Mater. 403 (2021) 123968. https://doi.org/10.1016/j.jhazmat.2020.123968.

[40] T.P. Thomsen, Z. Sárossy, J. Ahrenfeldt, U.B. Henriksen, F.J. Frandsen, D.S. Müller-Stöver, Changes imposed by pyrolysis, thermal gasification and incineration on composition and phosphorus fertilizer quality of municipal sewage sludge, J. Environ. Manage. 198 (2017) 308-318. https://doi.org/10.1016/j.jenvman.2017.04.072.

[41] J. Liu, J. Fu, X. Ning, S. Sun, Y. Wang, W. Xie, S. Huang, S. Zhong, An experimental and thermodynamic equilibrium investigation of the $\mathrm{Pb}, \mathrm{Zn}, \mathrm{Cr}, \mathrm{Cu}, \mathrm{Mn}$ and $\mathrm{Ni}$ partitioning during sewage sludge incineration, J. Environ. Sci. 35 (2015) 43-54. https://doi.org/10.1016/j.jes.2015.01.027.

[42] B. Nowak, P. Aschenbrenner, F. Winter, Heavy metal removal from sewage sludge ash and municipal solid waste fly ash - A comparison, Fuel Process. Technol. 105 (2013) 195-201. https://doi.org/10.1016/j.fuproc.2011.06.027.

[43] J. Han, P. Kanchanapiya, T. Sakano, T. Mikuni, M. Furuuchi, G. Wang, The behaviour of phosphorus and heavy metals in sewage sludge ashes, Int. J. Environ. Pollut. $37 \quad$ (2009) 357-368. https://doi.org/10.1504/IJEP.2009.026054.

[44] J. Liu, S. Huang, S. Sun, X. Ning, R. He, X. Li, T. Chen, G. Luo, W. Xie, Y. Wang, Z. Zhuo, J. Fu, Effects of sulfur on lead partitioning during sludge incineration based on experiments and thermodynamic calculations, Waste Manag. 38 (2015) 336-348. https://doi.org/10.1016/j.wasman.2014.11.021.

[45] H. Cai, J. Liu, J. Kuo, W. Xie, F. Evrendilek, G. Zhang, Ash-to-emission pollution controls on co-combustion of textile dyeing sludge and waste tea, Sci. Total Environ. $794 \quad$ (2021) 148667. https://doi.org/10.1016/j.scitotenv.2021.148667.

[46] F. Guo, Z. Zhong, H. Xue, Partition of Zn, Cd, and Pb during co-combustion of sedum plumbizincicola and sewage sludge, Chemosphere. 197 (2018) 50-56. https://doi.org/10.1016/j.chemosphere.2018.01.021.

[47] Y.T. Tang, X.Q. Ma, Q.H. Yu, C. Zhang, Z. Lai, X. Zhang, Heavy metal enrichment characteristics in ash of municipal solid waste combustion in CO2/O2 atmosphere, Waste Manag. 43 (2015) $247-254$. https://doi.org/10.1016/j.wasman.2015.06.024.

[48] K. Gorazda, B. Tarko, Z. Wzorek, A.K. Nowak, J. Kulczycka, A. Henclik, Characteristic of wet method of phosphorus recovery from polish sewage sludge ash with nitric acid, Open Chem. 14 (2016) 37-45. https://doi.org/10.1515/chem-2016-0006.

[49] L. Wang, G. Skjevrak, J.E. Hustad, M.G. Grønli, Sintering characteristics of sewage sludge ashes at elevated temperatures, Fuel Process. Technol. 96 (2012) 88-97. https://doi.org/10.1016/j.fuproc.2011.12.022.

[50] P.-Y. Mahieux, J.-E. Aubert, M. Cyr, M. Coutand, B. Husson, Quantitative mineralogical composition of complex mineral wastes - Contribution of the Rietveld method, Waste Manag. 30 (2010) 378-388. https://doi.org/10.1016/j.wasman.2009.10.023. 
[51] L. Chen, Y. Liao, X. Ma, S. Lu, Heavy metals chemical speciation and environmental risk of bottom slag during cocombustion of municipal solid waste and sewage sludge, J. Clean. Prod. 262 (2020) 121318. https://doi.org/10.1016/j.jclepro.2020.121318.

[52] H. Herzel, J. Stemann, S. Simon, C. Adam, Comparison of thermochemical treatment of sewage sludge ash with sodium sulphate in laboratory-scale and pilot-scale experiments, Int. J. Environ. Sci. Technol. (2021). https://doi.org/10.1007/s13762-021-03252-y.

[53] C. Schaum, P. Cornel, N. Jardin, Phosphorus recovery from sewage sludge ash - A wet chemical approach, in: Proceeding IWA Conf., June 24-27, Moncton, Canada, 2007: pp. 583-590.

[54] N. Semerci, S. Ahadi, S. Coşgun, Comparison of dried sludge and sludge ash for phosphorus recovery with acidic and alkaline leaching, Water Environ. J. 35 (2021) 359-370. https://doi.org/10.1111/wej.12633.

[55] H. Liu, G. Hu, I.A. Basar, J. Li, N. Lyczko, A. Nzihou, C. Eskicioglu, Phosphorus recovery from municipal sludgederived ash and hydrochar through wet-chemical technology: A review towards sustainable waste management, Chem. Eng. J. 417 (2021) 129300. https://doi.org/10.1016/j.cej.2021.129300.

[56] E. Levlin, B. Hultman, Phosphorus recovery from sewage sludge - Ideas for further studies to improve leaching, in: Proc. a Polish-Swedish Semin., June 6-8, Stockholm, Sweden, 2004: pp. 61-70.

[57] R. Huang, Y. Tang, Speciation dynamics of phosphorus during (hydro)thermal treatments of sewage sludge, Environ. Sci. Technol. 49 (2015) 14466-14474. https://doi.org/10.1021/acs.est.5b04140.

[58] A.A. Szögi, M.B. Vanotti, P.G. Hunt, Phosphorus recovery from pig manure solids prior to land application, J. Environ. Manage. 157 (2015) 1-7. https://doi.org/10.1016/j.jenvman.2015.04.010.

[59] S. Jeon, D.-J. Kim, Enhanced phosphorus bioavailability and heavy metal removal from sewage sludge ash through thermochemical treatment with chlorine donors, J. Ind. Eng. Chem. 58 (2018) $216-221$. https://doi.org/10.1016/j.jiec.2017.09.028.

[60] G. Fraissler, M. Jöller, H. Mattenberger, T. Brunner, I. Obernberger, Thermodynamic equilibrium calculations concerning the removal of heavy metals from sewage sludge ash by chlorination, Chem. Eng. Process. Process Intensif. 48 (2009) 152-164. https://doi.org/10.1016/j.cep.2008.03.009.

[61] A.-L. Elled, L.-E. Åmand, B. Leckner, B.-A. Andersson, Influence of phosphorus on sulphur capture during cofiring of sewage sludge with wood or bark in a fluidised bed, Fuel. 85 (2006) 1671-1678. https://doi.org/10.1016/j.fuel.2006.02.008.

[62] D. Lindberg, R. Backman, P. Chartrand, M. Hupa, Towards a comprehensive thermodynamic database for ashforming elements in biomass and waste combustion - Current situation and future developments, Fuel Process. Technol. 105 (2013) 129-141. https://doi.org/10.1016/j.fuproc.2011.08.008.

[63] M. Reinmöller, M. Klinger, M. Schreiner, H. Gutte, Relationship between ash fusion temperatures of ashes from hard coal, brown coal, and biomass and mineral phases under different atmospheres: A combined FactSage ${ }^{\mathrm{TM}}$ computational and network theoretical approach, Fuel. $151 \quad$ (2015) $118-123$. https://doi.org/10.1016/j.fuel.2015.01.036.

[64] J. Li, Q. Xue, L. Fang, C.S. Poon, Characteristics and metal leachability of incinerated sewage sludge ash and air pollution control residues from Hong Kong evaluated by different methods, Waste Manag. 64 (2017) $161-170$. https://doi.org/10.1016/j.wasman.2017.03.033.

[65] M. Pazos, G.M. Kirkelund, L.M. Ottosen, Electrodialytic treatment for metal removal from sewage sludge ash from fluidized bed combustion, J. Hazard. Mater. 176 (2010) 1073-1078. https://doi.org/10.1016/j.jhazmat.2009.11.150.

[66] Z. Xiao, X. Yuan, H. Li, L. Jiang, L. Leng, X. Chen, G. Zeng, F. Li, L. Cao, Chemical speciation, mobility and phyto-accessibility of heavy metals in fly ash and slag from combustion of pelletized municipal sewage sludge, Sci. Total Environ. 536 (2015) 774-783. https://doi.org/10.1016/j.scitotenv.2015.07.126.

[67] B. Verbinnen, P. Billen, C. Vandecasteele, Thermal treatment of solid waste in view of recycling: Chromate and molybdate formation and leaching behaviour, Waste Manag. Res. 32 (2014) 536-542. https://doi.org/10.1177/0734242X14532004.

[68] J. Latosińska, P. Czapik, The ecological risk assessment and the chemical speciation of heavy metals in ash after the incineration of municipal sewage sludge, Sustainability. 12 (2020) 6517. https://doi.org/10.3390/su12166517.

[69] J. Li, D.C.W. Tsang, Q. Wang, L. Fang, Q. Xue, C.S. Poon, Fate of metals before and after chemical extraction of $\begin{array}{llllll}\text { incinerated sewage } & \text { sludge } & \text { ash, } & \text { Chemosphere. } & 186 & \text { (2017) }\end{array}$ https://doi.org/10.1016/j.chemosphere.2017.08.012.

[70] J. Li, J. Gan, Y. Hu, Characteristics of heavy metal species transformation of $\mathrm{Pb}, \mathrm{Cu}, \mathrm{Zn}$ from municipal sewage sludge by thermal drying, Procedia Environ. Sci. 31 (2016) 961-969. https://doi.org/10.1016/j.proenv.2016.03.001.

[71] K. Shih, T. White, J.O. Leckie, Nickel stabilization efficiency of aluminate and ferrite spinels and their leaching behavior, Environ. Sci. Technol. 40 (2006) 5520-5526. https://doi.org/10.1021/es0601033.

[72] K. Huang, K. Inoue, H. Harada, H. Kawakita, K. Ohto, Leaching of heavy metals by citric acid from fly ash generated in municipal waste incineration plants, J. Mater. Cycles Waste Manag. 13 (2011) 118-126. https://doi.org/10.1007/s10163-011-0001-5. 
[73] M. Takahashi, S. Kato, H. Shima, E. Sarai, T. Ichioka, S. Hatyakawa, H. Miyajiri, Technology for recovering phosphorus from incinerated wastewater treatment sludge, Chemosphere. 44 (2001) 23-29. https://doi.org/10.1016/S0045-6535(00)00380-5.

[74] X. Lu, K. Shih, Formation of lead-aluminate ceramics: Reaction mechanisms in immobilizing the simulated lead sludge, Chemosphere. 138 (2015) 156-163. https://doi.org/10.1016/j.chemosphere.2015.05.090.

[75] J. Liu, Z. Zhuo, W. Xie, J. Kuo, X. Lu, M. Buyukada, F. Evrendilek, Interaction effects of chlorine and phosphorus on thermochemical behaviors of heavy metals during incineration of sulfur-rich textile dyeing sludge, Chem. Eng. J. 351 (2018) 897-911. https://doi.org/10.1016/j.cej.2018.06.158.

[76] K. Huang, K. Inoue, H. Harada, H. Kawakita, K. Ohto, Leaching behavior of heavy metals with hydrochloric acid from fly ash generated in municipal waste incineration plants, Trans. Nonferrous Met. Soc. China. 21 (2011) 14221427. https://doi.org/10.1016/S1003-6326(11)60876-5.

[77] A.M.J. Kootstra, D.W.F. Brilman, S.R.A. Kersten, Dissolution of phosphate from pig manure ash using organic and mineral acids, Waste Manag. 88 (2019) 141-146. https://doi.org/10.1016/j.wasman.2019.03.038. 